ACCEPTED MANUSCRIPT

\title{
Impurity-enhanced solid-state amorphization: the Ni-Si thin film reaction altered by nitrogen
}

To cite this article before publication: Koen van Stiphout et al 2019 J. Phys. D: Appl. Phys. in press https://doi.org/10.1088/1361-6463/ab00d2

\section{Manuscript version: Accepted Manuscript}

Accepted Manuscript is "the version of the article accepted for publication including all changes made as a result of the peer review process, and which may also include the addition to the article by IOP Publishing of a header, an article ID, a cover sheet and/or an 'Accepted

Manuscript' watermark, but excluding any other editing, typesetting or other changes made by IOP Publishing and/or its licensors"

This Accepted Manuscript is @ 2019 IOP Publishing Ltd.

During the embargo period (the 12 month period from the publication of the Version of Record of this article), the Accepted Manuscript is fully protected by copyright and cannot be reused or reposted elsewhere.

As the Version of Record of this article is going to be / has been published on a subscription basis, this Accepted Manuscript is available for reuse under a CC BY-NC-ND 3.0 licence after the 12 month embargo period.

After the embargo period, everyone is permitted to use copy and redistribute this article for non-commercial purposes only, provided that they adhere to all the terms of the licence https://creativecommons.org/licences/by-nc-nd/3.0

Although reasonable endeavours have been taken to obtain all necessary permissions from third parties to include their copyrighted content within this article, their full citation and copyright line may not be present in this Accepted Manuscript version. Before using any content from this article, please refer to the Version of Record on IOPscience once published for full citation and copyright details, as permissions will likely be required. All third party content is fully copyright protected, unless specifically stated otherwise in the figure caption in the Version of Record.

View the article online for updates and enhancements. 
1

2

3

4

5

6

7

8

9

10

11

12

13

14

15

16

17

\section{Impurity-enhanced solid-state amorphization: the Ni-Si thin film reaction altered by} nitrogen

K. van Stiphout, ${ }^{1}$ F.A. Geenen, ${ }^{2}$ N.M. Santos, ${ }^{1}$ S.M.C. Miranda, ${ }^{1}$ V. Joly, ${ }^{1}$ J.

Demeulemeester, ${ }^{1}$ C. Detavernier, ${ }^{2}$ F. Kremer, ${ }^{3}$ L.M.C. Pereira, ${ }^{1}$ K. Temst, ${ }^{1}$ and A. Vantomme ${ }^{1}$

1) KU Leuven, Instituut voor Kern- en Stralingsfysica, 3001 Leuven, Belgium

${ }^{2)}$ Ghent University, Department of Solid State Sciences, Krijgslaan 281/S1, 9000 Ghent, Belgium

${ }^{3)}$ Dept. of Electronic Materials Engineering, RSPE, Australian National University, Canberra ACT 2601, Australia

(Dated: 16 January 2019)

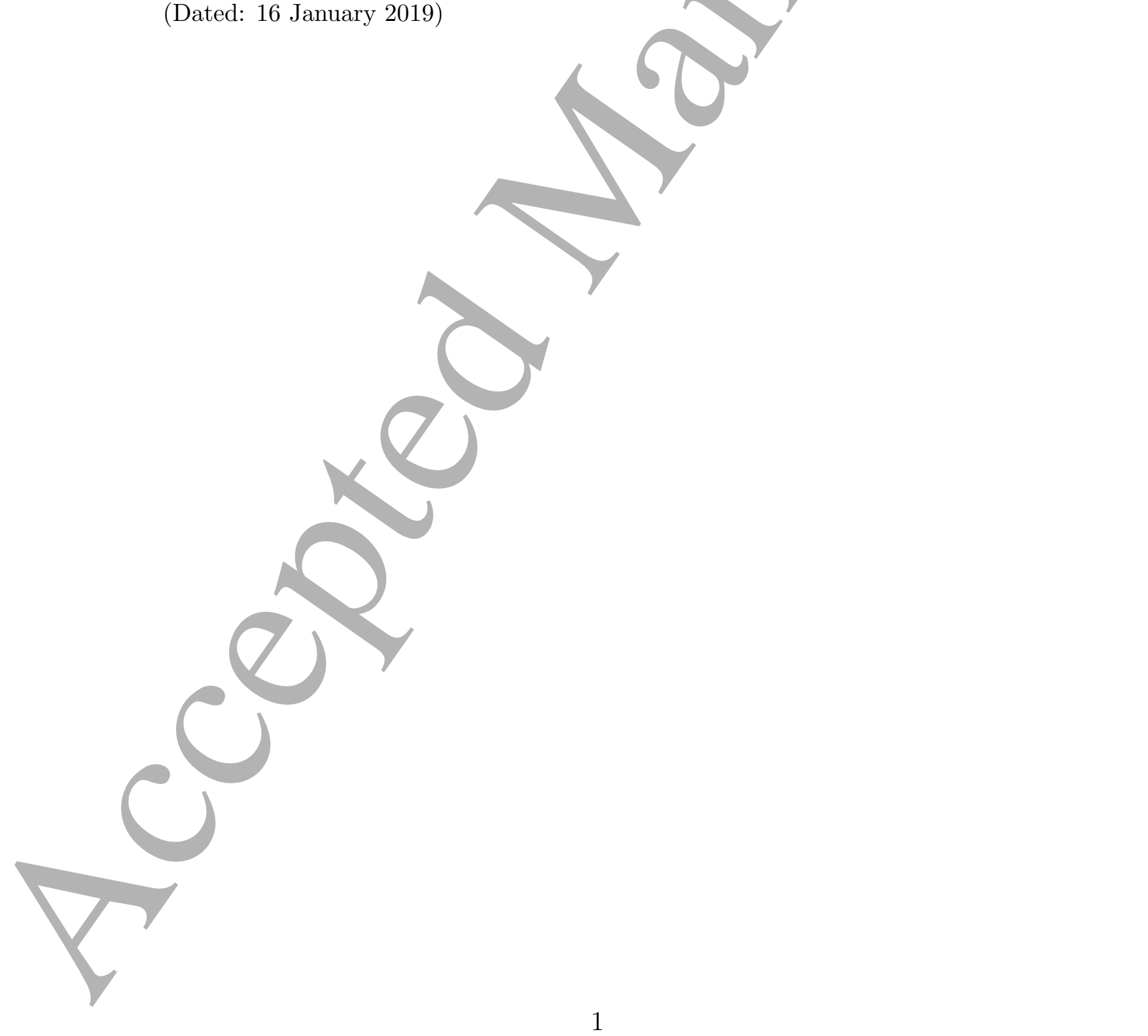


Solid-state amorphization, the growth of an amorphous phase during annealing, has been studied in a wide variety of thin film structures. Whereas research on the remarkable growth of such a metastable phase has mostly focused on strictly binary systems, far less is known about the influence of impurities on such reactions. In this paper, the influence of nitrogen, introduced via ion implantation, is studied on the solid-state amorphization reaction of thin $(35 \mathrm{~nm}) \mathrm{Ni}$ films with $\mathrm{Si}$, using in situ XRD, ex situ RBS, XTEM, and synchrotron XRD. It is shown that due to small amounts of nitrogen $(<2$ at.\%), an amorphous Ni-Si phase grows almost an order of magnitude thicker during annealing than for unimplanted samples. Nitrogen hinders the nucleation of the first crystalline phases, leading to a new reaction path: the formation of the metal-rich crystalline silicides is suppressed in favour of an amorphous Ni-Si alloy; during a brief temperature window between 330 and $350^{\circ} \mathrm{C}$, the entire film is converted to an amorphous phase. The first crystalline structure to grow is the orthorhombic NiSi phase. We demonstrate that this phenomenon occurs only under specific implantation conditions. In particular, the initial distribution of nitrogen upon implantation is crucial: sufficient nitrogen impurities must be present at the interface throughout the reaction. Introducing implantation damage without nitrogen impurities (e.g. by implanting a noble gas) does not cause the enhanced solid-state reaction. Moreover, we show that the stabilizing effect of nitrogen on amorphous Ni-Si films (with a composition ranging from $40 \%$ to $50 \% \mathrm{Si}$ ) is not restricted to thin film reactions, but is a general feature of the Ni-Si system. 


\section{INTRODUCTION}

Thin film growth has been studied extensively for several decades. ${ }^{1-3}$ One particular way of growing thin films is to anneal two elemental films (or a film and a substrate) which are in contact which each other, creating compounds at the interface during the solid-state reaction. Special attention was given to reactions between a metal layer and Si substrates, due to the role of metal silicide growth as model system for solid-state reactions. Many studies and models $^{2,4,5}$ focus on the reaction path of binary systems during annealing, from the initial deposition of the metal layer to the system reaching thermal equilibrium, e.g. the evolution of a Co-Ti bilayer to an epitaxial $\mathrm{CoSi}_{2}$ film. ${ }^{6}$ This path is bound by thermodynamic and kinetic constraints and as a result, the first phase formed at the interface is often not the phase which would be expected in thermal equilibrium. Solid-state reactions are typically a succession of several phases, until a phase is reached/which is stable in contact with the substrate. Moreover, due to the aforementioned constraints, the growth of metastable phases has been observed in many metal/Si reactions: phases which have a larger Gibbs free energy than another phase (or a combination of phases) of identical composition, such as the $\epsilon$-FeSi phase ${ }^{7}$ or the hexagonal $\theta-\mathrm{Ni}_{2} \mathrm{Si}$ phase (sometimes also referred to as the the $\theta$ phase). ${ }^{8}$ Another example of a binary reaction involving metastable phases is a solid-state amorphization (SSA) reaction: upon annealing, the first interlayer formed is an amorphous phase, even when one or both parent phases are (poly)crystalline. ${ }^{9}$ Since its discovery in the early 1980's, ${ }^{10,11}$ several binary metal/Si and metal/metal systems undergoing this type of reaction have been identified.

As binary reactions of elemental thin films have become better understood, attention is turning to ternary systems. In these systems, a third element is introduced, e.g. during deposition or via ion implantation. When the concentration of the third element constitutes only a few atomic percent, the system is typically considered a binary system containing impurities. It has been shown ${ }^{12}$ that reactions can be modified by impurities, with respect to the reaction path, the reaction rate or the stability of metastable states. Efforts to understand the effects of impurities on metal silicide formation are ongoing. $3,13,14$

Surprisingly, very little is known about the effect of impurities on the SSA reaction. J.J. 
Hauser $^{15}$ showed that impurities, originating from residual gas present in the vacuum system, play an important role in the nucleation of an amorphous phase in the Ni-Zr system. Other reports, focusing on the growth of the amorphous phase following its nucleation, show that impurities can either enhance ${ }^{16}$ or diminish ${ }^{17}$ the growth of the amorphous phase in metal/metal or metal/Si couples. However, few cases have been studied, and a general understanding of the impurity effect on SSA reactions is lacking.

One binary reaction that has been studied extensively, is that of thin Ni films with silicon. ${ }^{18,19}$ This reaction has proven scientifically interesting, with the appearance of metastable phases, ${ }^{8}$ a strong interplay between texture and film evolution, ${ }^{20}$ and a nucleation-limited growth of the final phase. ${ }^{21}$ Additionally, investigation of this reaction is partly driven by the use of NiSi films as contact material in CMOS architecture. ${ }^{3,2}$ The Ni-Si reaction is also a promising test case for the effect of impurities on the SSA reaction: it has been reported ${ }^{23}$ that the reaction of the $\mathrm{Ni}$-Si system starts off with the growth of an amorphous phase (see below). Moreover, it has been shown that the Ni-Si reaction can be strongly affected by impurities, ${ }^{24}$ such as nitrogen, ${ }^{25}$ carbon $^{26}$ and oxygen. ${ }^{27}$

Below, we briefly discuss the most prominent (general) models of solid-state amorphization reactions, nucleation in thin film reaction and the growth of an amorphous interlayer in the Ni-Si system specifically.

\section{A. General considerations on SSA}

Solid-state amorphization has been studied in many binary systems, both in metal/metal and metal/Si couples. Based on experimental evidence, two required conditions for a SSA reaction have been identified: ${ }^{9}$

1. The formation of an amorphous interlayer must have a negative enthalpy of mixing.

2. The diffusivity of one element in the other must be asymmetrically high.

These conditions represent the thermodynamic and kinetic prerequisites for a SSA reaction, respectively. It is often found that when the diffusivity of element $\mathrm{A}$ in element $\mathrm{B}$ is very high, the diffusivity of $\mathrm{A}$ in the amorphous alloy $\mathrm{A}_{x} \mathrm{~B}_{y}$ is high as well. ${ }^{9}$ Hence, a likely consequence of the second condition is an anomalously fast diffusion of the mobile element 
These two interpretations are not mutually exclusive,${ }^{30}$ e.g. in a system in which crystalline phases are initially unable to nucleate, the rate at which a growing amorphous phase lowers the free energy $\Delta \mathrm{G}$ is (trivially) higher than that of the crystalline phases (which cannot grow). In this respect, the first interpretation (i.e. nucleation barriers cause the SSA reaction) can be thought of as a specific case of the more general second interpretation of growth instability. Other models for $\mathrm{SSA}^{32,33}$ often hold an intermediate view, comparing

the thickening rate of the amorphous phase to the nucleation rate of the crystalline phases. phase. These conditions can also be generalized to include ternary systems (or systems with even more elements), by requiring that one element is a fast diffuser in the other two (or more) elements, e.g. the fast diffusion of hydrogen in Rh-Zr compounds. ${ }^{28}$

The first condition provides a driving force for the amorphous phase growth. The interpretation of the second, kinetic condition is less obvious, and has led to two (related) schools of thought as to why an amorphous phase is the first to grow at the metal/Si interface in these systems. The first school ${ }^{9,29}$ considers that the amorphous phase grows at temperatures too low for crystalline phases to nucleate. Consequently, it/implies that nucleation barriers to the formation of the first crystalline phase exist, whose origin will be discussed below. The second school ${ }^{30,31}$ makes no assumption concerning these barriers; it considers scenarios in which the nucleation of a crystalline phase is not necessarily an issue. Rather, this school focuses on the kinetic competition between phases. It assesses that the first phase to grow is that which has the highest rate of lowering the system's Gibbs free energy $(-\mathrm{d} \Delta \mathrm{G} / \mathrm{dt})$. Other phases, even if they can overcome nucleation barriers, are consumed by the first (fast-growing) phase. In other words, the formation of other phases is suppressed due to a growth instability, unitil the growth of the first phase (inversely proportional to its thickness) sufficiently slows down. ${ }^{4,30}$ For systems in which the second condition is met, the amorphous phase wins against any other (crystalline) phase that might nucleate: despite a lower driving force, it has the highest lowering rate due to its rapid growth. Consequently, the amorphous phase grows first and crystalline phases are suppressed until the amorphous phase has reached a certain critical thickness. 


\section{B. Nucleation barriers}

In thin film reactions, converting the film to a new phase requires that small nuclei of this phase first form, i.e. the new phase must nucleate. As noted above, nucleation barriers can be responsible for the solid-state amorphization in a number of systems. However, such barriers could be thermodynamic or kinetic in nature. Nucleation and its role in metal/Si systems, has been discussed most notably by d'Heurle. ${ }^{34}$ The rate of nucleation, $\dot{N}$, is proportional to

$$
\begin{array}{r}
\dot{N} \propto \exp \left(-\frac{\Delta G^{*}}{k_{B} T}\right) \exp \left(-\frac{Q}{k_{B} T}\right) \\
\text { with } \Delta G^{*}=\frac{\Delta \sigma^{3}}{(\Delta H-T \Delta S)^{2}} \cdot
\end{array}
$$

$\Delta \sigma, \Delta \mathrm{H}$ and $\Delta \mathrm{S}$ denote the respective change in interface energy, enthalpy and entropy due to the phase transition. These factors determine $\Delta G^{*}$, the energetic barrier imposed by the creation of new interfaces. Q represents the activation energy for the (short-range) diffusion needed to form the nuclei. Indeed, the atoms must rearrange themselves into the particular microstructure of the new phase, e.g. atoms hopping into their substitutional positions in the new crystal lattice. Each exponent represents a different barrier to nucleation: the first is thermodynamic in nature $\left(\Delta \mathrm{G}^{*}\right)$, the second kinetic $(\mathrm{Q})$. Typically, thermodynamic nucleation barriers are only significant during the later stages of the reaction, when the enthalpy of formation $\Delta \mathrm{H}$ is low. ${ }^{34}$ In contrast, the kinetics barrier $\mathrm{Q}$ play a role at the very beginning of the reaction. Indeed, at low temperatures, atoms have low thermal energy and are slow to rearrange themselves into the crystal lattice.

Although all silicide formation requires some form of atomic rearrangement, the lowtemperature nucleation barrier $\mathrm{Q}$ can be a crucial factor in systems which undergo SSA. Indeed, a significant discrepancy in mobility between the different elements (the second condition for SSA, section IA) means that the diffusion-limited growth of the amorphous phase (proportional to the long-range mobility of the fast element) can occur at lower temperature than the nucleation of crystalline phases (proportional to the short-range mobility of all elements, including the slow ones). 


\section{SSA reaction in Ni-Si system}

The Ni-Si system meets both criteria for SSA noted above: the estimated heat of formation for an amorphous Ni-Si phase is $-12 \pm 5 \mathrm{~kJ} / \mathrm{mol},{ }^{35}$ and $\mathrm{Ni}$ is indeed a fast diffuser in $\mathrm{Si}^{36}$ and in the amorphous phase, ${ }^{37}$ whereas diffusion of $\mathrm{Si}$ in $\mathrm{Ni}$ and $\mathrm{Si}$ self-diffusion is significantly slower. ${ }^{37,38}$ With both conditions met, one can expect this system to undergo SSA. Indeed, an amorphous Ni-Si interlayer forms at the interface during deposition and thickens upon annealing, both on amorphous ${ }^{39}$ and single-crystalline ${ }^{40}$ substrates. Depending on the experimental conditions, this amorphous layer can reach a thickness of several $\mathrm{nm}$ (thicknesses up to $10 \mathrm{~nm}$ have been reported) ${ }^{23}$ before crystallizing and has a composition close to $1: 1 .^{41}$ Once the nucleation of the first crystalline phase occurs $\left(\delta-\mathrm{Ni}_{2} \mathrm{Si}\right)$, both phases grow side by side at the expense of the Ni film. When the temperature is raised by a few tens of degrees, the amorphous phase crystallizes, ${ }^{23}$ and the reaction proceeds via a succession of crystalline phases, ending with the $\mathrm{NiSi}_{2}$ phase. ${ }^{21}$

The existence of nucleation barriers to the first crystalline phase $\delta-\mathrm{Ni}_{2} \mathrm{Si}$ has been experimentally verified using differential calorimetry scanning. ${ }^{39,41}$ Hence, for the Ni-Si system, the inability of crystalline phases to nucleate at low temperatures (rather than growth instability of the crystalline phases, cf. section IA) allows an amorphous phase to thicken up to several nm. Despite some controversy, ${ }^{42}$ these barriers are kinetic in nature, i.e. the term Q in Eq. 1 is the dominant term. Indeed, d'Heurle ${ }^{34}$ cites the Ni-Si system explicitly as illustration why the (thermodynamic) nucleation barrier $\Delta \mathrm{G}^{*}$ is almost completely negligible at the earliest stages of silicide formation.

It is well-documented that the addition of impurities can influence the reaction of a binary system of the Ni-Si system and the properties of the resulting films, ${ }^{12}$ such as the morphological stability of the NiSi films ${ }^{24}$ or the diffusion of the mobile element Ni through the silicide films. ${ }^{18}$ However, little is known about the effect of impurities on the Ni-Si SSA reaction. In this paper, we investigate the effect of an impurity (specifically, nitrogen) on the solid-state amorphization during silicide formation (specifically, the reaction of thin Ni films with $\mathrm{Si}$ ). We will show that the growth of the amorphous Ni-Si phase can be significantly 


\section{EXPERIMENTAL}

A number of sample batches were produced, for different purposes. For all samples, $\mathrm{Si}(100)$ substrates were cleaned using the standard Radio Corporation America (RCA) procedure, dipped in $\mathrm{HF}(2 \%)$, and immediately loaded into ultra-high vacuum $\left(\leq 10^{-9} \mathrm{mbar}\right)$. In sections IIIA and III B, all samples shown consisted of a $35 \mathrm{~nm} \mathrm{Ni}$ film, evaporated onto a $\mathrm{Si}(100)$ substrate, except for the $80 \mathrm{~nm}$ Ni film evaporated onto a $\mathrm{Si}(100)$ substrate (details below). In section III C, a $30 \mathrm{~nm}$ amorphous Si layer was evaporated first, followed by co-deposition of $\mathrm{Ni}$ and $\mathrm{Si}$ to achieve a $35 \mathrm{~nm}$ mixture of $\mathrm{Ni}$ and $\mathrm{Si}$ with a specific stoichiometry, on amorphous Si. The purity, composition and thickness of the deposited films were checked using Rutherford backscattering spectrometry (RBS, see below), assuming bulk density of the $\mathrm{Ni}$ or $\mathrm{Si}$, or a weighted average of $\mathrm{Ni}$ and $\mathrm{Si}$ in case of the Ni-Si mixtures. As the real density of the films might differ (particularly for the mixtures of $\mathrm{Ni}$ and $\mathrm{Si}$ ), the 
reported values could differ slightly from their real values.

Ion implantation was achieved using a high-current Danfysik implanter. ${ }^{45}$ The ion beam was swept across the sample surface and four faraday cups positioned around the sample; these cups measured the implanted fluence. Moreover, charge collection and uniformity across the sample surface were checked prior by implanting $\mathrm{Fe}^{+}$into a Si wafer and confirming the fluence (uniformity) using RBS. $\mathrm{N}_{2}^{+}$was implanted at an energy of 30 or $40 \mathrm{keV} /$ atom to a fluence ranging from $1 \times 10^{15}$ to $1.5 \times 10^{16} \mathrm{~N} / \mathrm{cm}^{2}$ (details below). The current density was kept below $0.6 \mu \mathrm{A} / \mathrm{cm}^{2}$ to avoid excessive heating of the samples. $\mathrm{N}_{2}^{+}$was implanted after the film deposition, unless mentioned otherwise. In other experiments (some of which are shown in the supplementary information, Fig. S2), $\mathrm{Ar}^{+}$ions were implanted at an energy ranging from 25 to $80 \mathrm{keV}$, to a fluence ranging from $0.3 \times 10^{13}$ to $1 \times 10^{16} \mathrm{Ar} / \mathrm{cm}^{2}$, both before and after film deposition. During implantation, the samples were rotated $7^{\circ}$ with respect to the ion beam, to minimize ion channelling. After implantation, nitrogen is spread throughout the Ni layer and the Si underneath. To illustrate the distribution of the impurity as-implanted, TRIM calculations (SRIM-2013) ${ }^{46}$ were performed for a $35 \mathrm{~nm} \mathrm{Ni}$ film on $\mathrm{Si}(100)$ (Fig. 1(a)) and a Ni-Si mixture on Si (Fig. 1(b)). At the interface, a small discontinuity in nitrogen concentration can be seen due to the difference in stopping power at either side of the interface.

In situ X-ray diffraction (XRD) was performed in a $\mathrm{He}\left(+5 \% \mathrm{H}_{2}\right)$ ambient, using a heating rate of $0.5^{\circ} \mathrm{C} / \mathrm{s}$, unless stated otherwise. Diffraction of the $\mathrm{CuK}_{\alpha}$ radiation $(\lambda=1.54 \AA)$ was recorded with a linear detector (Vantec D8) spanning $20^{\circ}$ in $2 \theta .^{47}$ Ex situ, high-resolution XRD was performed at the DiffAbs beamline ${ }^{48}$ at the Soleil synchrotron $(\lambda=1.54 \AA)$. Using a 6-circle goniometer and a X-ray pixel area detector (XPAD), a large section of reciprocal space can be probed in a short timeframe. ${ }^{48}$ For direct comparison, the diffraction angles have been converted to d-spacing.

The sample for transmission electron microscopy (TEM) was prepared for cross-section observation using conventional dimple grinding and ion milling in order to achieve final electron transparency. The TEM micrographs were acquired using a Jeol 2100F operating at $200 \mathrm{kV}$. The lattice images were recorded with the sample aligned with the [011] zone 

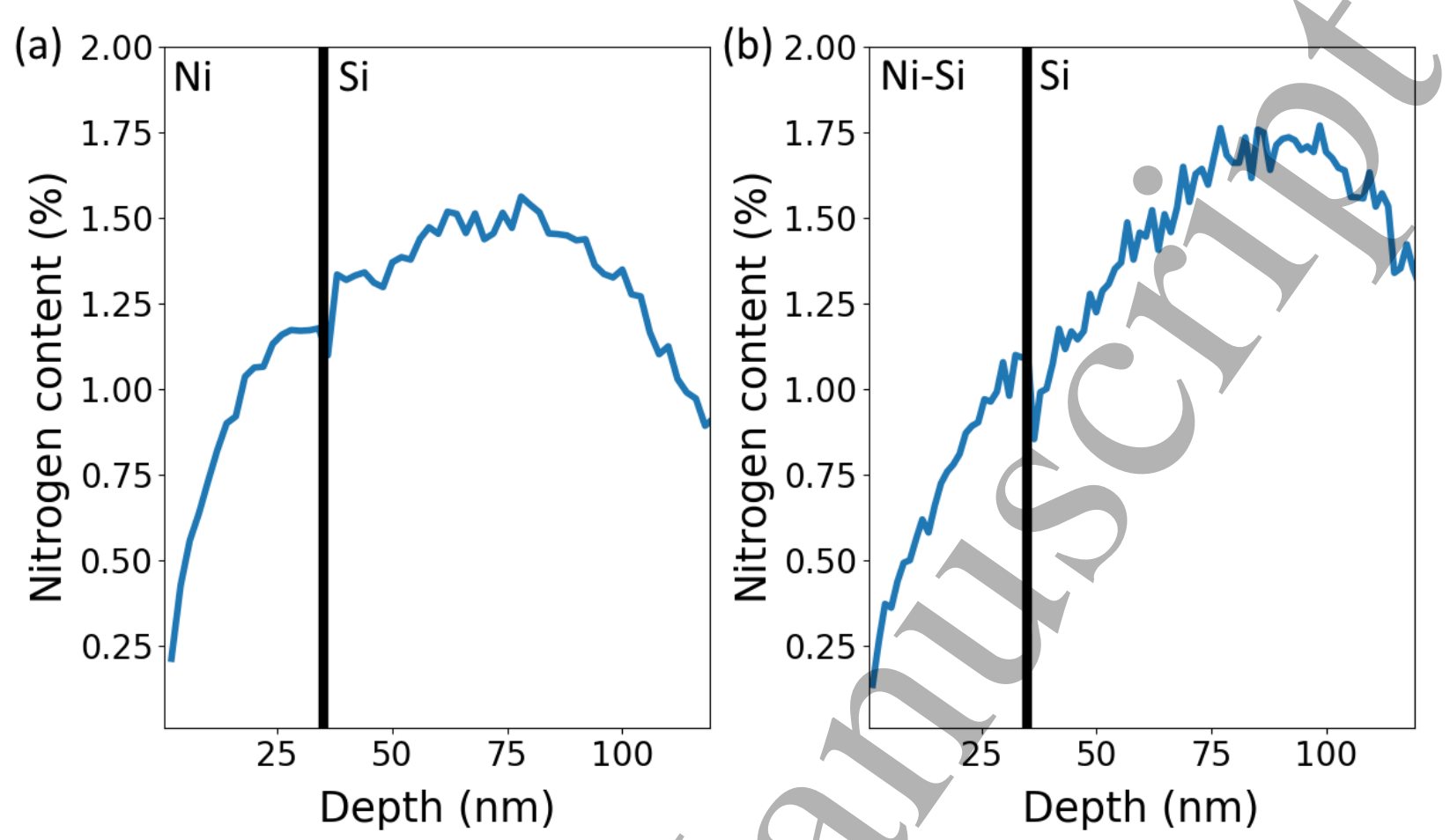

FIG. 1. TRIM calculations of the nitrogen distribution throughout the film and substrate, after implantation. (a) $1 \times 10^{16} \mathrm{~N} / \mathrm{cm}^{2}$ implanted at $40 \mathrm{keV} /$ atom into a $35 \mathrm{~nm}$ Ni film on Si. (b) $1 \times 10^{16} \mathrm{~N} / \mathrm{cm}^{2}$ implanted at $40 \mathrm{keV} /$ atom into a $35 \mathrm{~nm} \mathrm{Ni-Si}$ film $(46 \% \mathrm{Si})$ on $\mathrm{Si}$.

axis of the silicon substrate.

Rutherford backscattering spectrometry (RBS) was performed using a $\mathrm{He}^{+}$beam with an energy of $1.57 \mathrm{MeV}$ and a current of $20 \mathrm{nA}$. Spectra were recorded using a PIPS detector with an energy resolution of $15 \mathrm{keV}$. The ion beam, sample normal and detector were kept in the same plain. The incident angle of the ion beam onto the sample was $25^{\circ}$ to the sample normal, the exit angle was $38^{\circ}$ and the backscattering angle was $168^{\circ}$.

\section{RESULTS}

Our results section is divided into three parts. First, we show that after nitrogen implantation, the entire $35 \mathrm{~nm} \mathrm{Ni}$ film is converted to an amorphous Ni-Si layer upon annealing. Second, we demonstrate the implantation conditions (and consequently, the initial nitrogen distribution) required to induce the enhanced SSA reaction. Finally, we will explore the influence of nitrogen on the stability of amorphous Ni-Si films grown by (co)deposition rather 
(a)

than by thin film reaction.

FIG. 2. In situ XRD measurements of the reaction of a $35 \mathrm{~nm} \mathrm{Ni}$ film on $\mathrm{Si}(100)$ for (a) an unimplanted sample and (b) a sample implanted with $1 \times 10^{16} \mathrm{~N} / \mathrm{cm}^{2}$ at $40 \mathrm{keV} /$ atom.

(b)

$\theta-\mathrm{Ni}_{2} \mathrm{Si}(110) \rightarrow \quad \quad \quad \mathrm{NiSi}(211)$

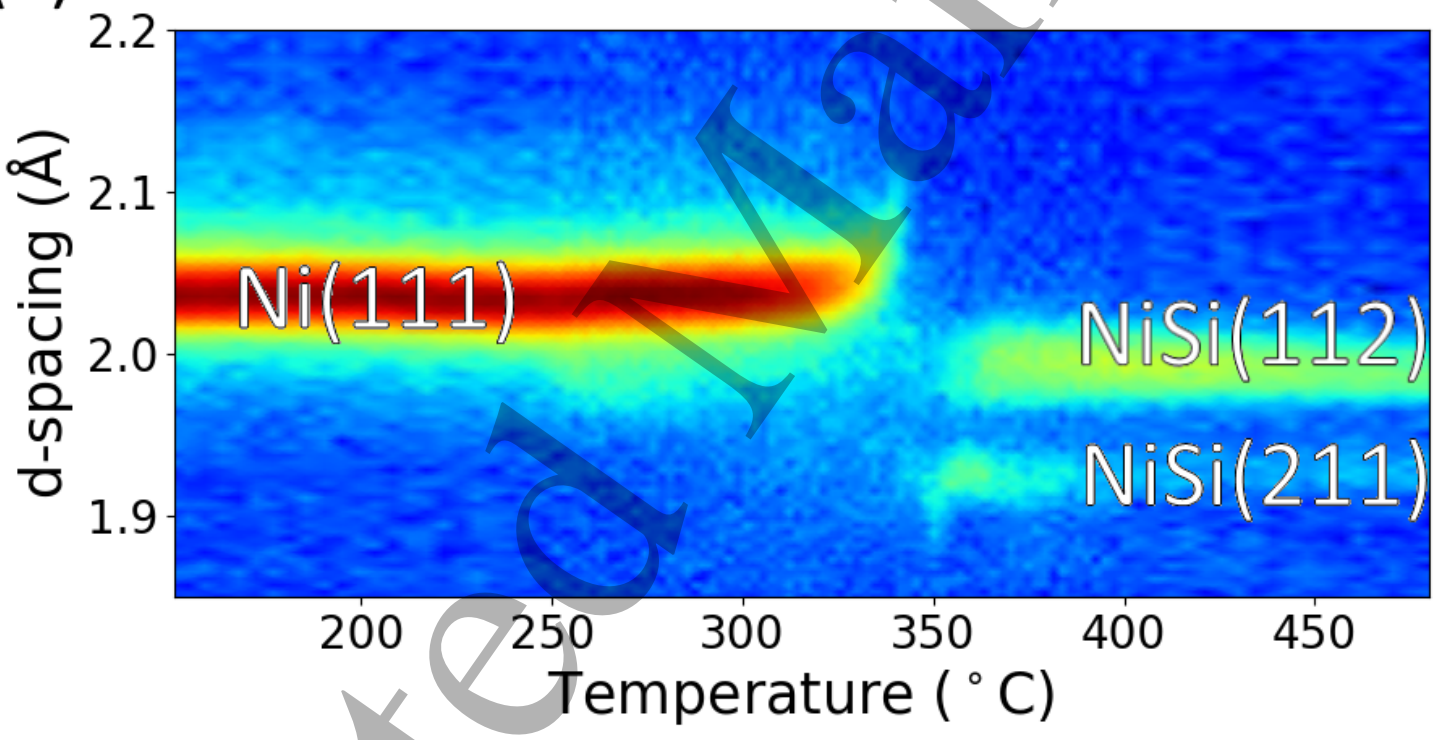




\section{A. Extended growth of amorphous phase during thin film reaction}

The solid-phase reaction of $35 \mathrm{~nm} \mathrm{Ni}$ on $\mathrm{Si}$ substrates with and without $\mathrm{N}_{2}$ implantation were recorded with in situ XRD (Fig. 2). Without implantation, the reaction starts with the growth of Ni-rich, crystalline silicides at the expense of the Ni layer, followed by a conversion to a NiSi film. ${ }^{19}$ Implantation of $1 \times 10^{16} \mathrm{~N} / \mathrm{cm}^{2}$ at $40 \mathrm{keV} /$ atom alters the reaction significantly: upon annealing, the $\mathrm{Ni}$ diffraction peak disappears around $340^{\circ} \mathrm{C}$, followed by a brief temperature window during which little or no diffraction is seen; none of the diffraction peaks of the typical metal-rich silicides $\left(\delta-\mathrm{Ni}_{2} \mathrm{Si}\right.$ and $\left.\theta-\mathrm{Ni}_{2} \mathrm{Si}\right)$ are unambiguously observed. At around $350^{\circ} \mathrm{C}$, diffraction peaks originating from the NiSi phase emerge, which is the only silicide phase at $440^{\circ} \mathrm{C}$, as further confirmed by ex situ XRD.

To understand which phase formed during the brief temperature window between the consumption of $\mathrm{Ni}$ and the growth of the NiSi phase (Fig. 2(b)), a number of samples, all implanted with $1 \times 10^{16} \mathrm{~N} / \mathrm{cm}^{2}$ at 30 or $40 \mathrm{keV} /$ atom, were quenched. These samples were subsequently investigated ex situ by TEM (Fig. 3, quenched at $330^{\circ} \mathrm{C}$ ), synchrotron XRD (Fig. 4, quenched at $340^{\circ} \mathrm{C}$ ) and RBS (Fig. 5, quenched at $340^{\circ} \mathrm{C}$ ).

The TEM images (Fig. 3) show that the film is almost entirely converted to a thick amorphous Ni-Si alloy, as confirmed by selected area electron diffraction (SAED) measurements (see supplementary information, Fig. S3). At the surface, a few grains of unreacted Ni can still be seen, alongside some grains of a crystalline silicide whose crystal structure could not be identified (Fig. 3(a)). Most of the $\sim 50 \mathrm{~nm}$ film however, consists of an amorphous Ni-Si alloy, spanning from the surface to the interface (Fig. 3(b)). The interface of the amorphous layer with the substrate is very flat, a phenomenon typical of diffusion-limited phase growth. It is further evidenced that the layer grew by the (sole) rapid diffusion of Ni through the layer, rather than by any other process, e.g. ion beam mixing (see also the supplementary information, Fig. S4). This is contrasted by the a-Si/c-Si interface, at which end-of-range defects due to the nitrogen implantation are still present. At $340^{\circ} \mathrm{C}$, (nitrogen-implanted) amorphous silicon does not recrystallize at laboratory time scales, ${ }^{50}$ hence this interface did not move during annealing. Indeed, both ion channelling measurements (not shown) and 
(a)

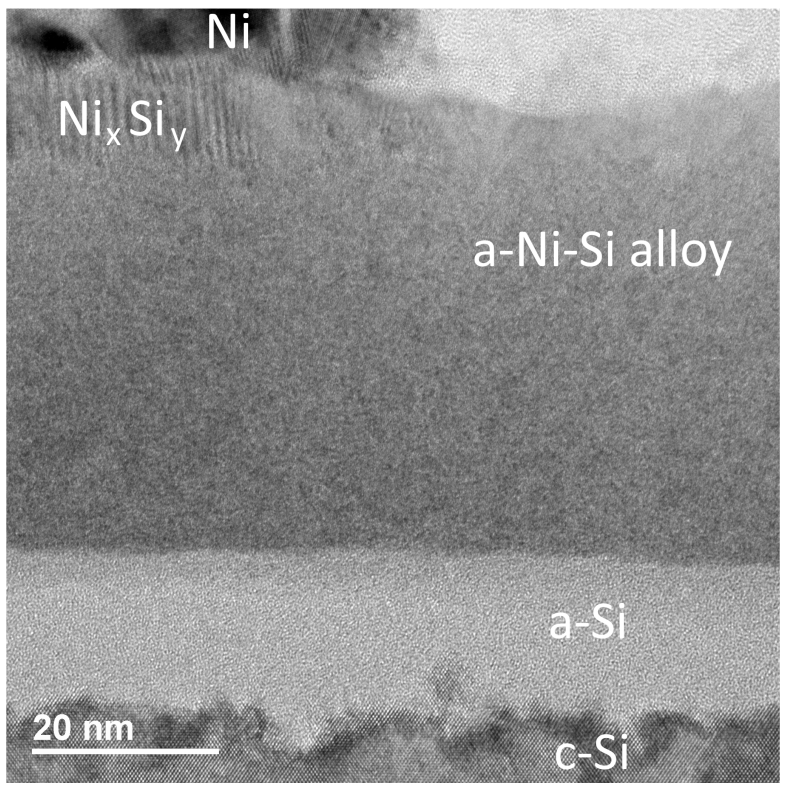

(b)

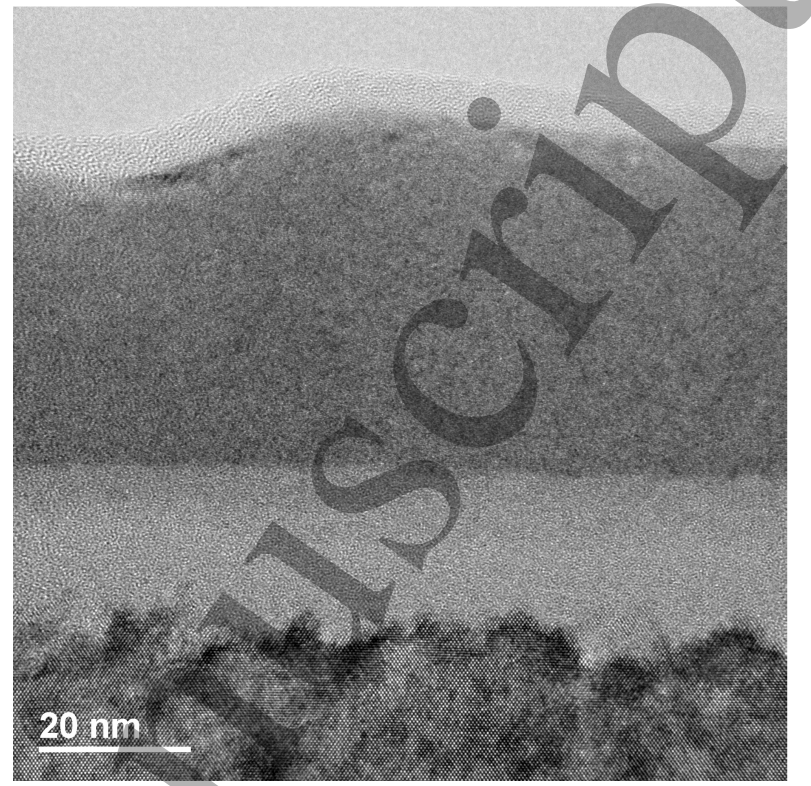

\section{C}

FIG. 3. TEM images of a $35 \mathrm{~nm}$ Ni film on Si(100) implanted with $1 \times 10^{16} \mathrm{~N} / \mathrm{cm}^{2}$ at $30 \mathrm{keV} /$ atom and annealed to $330^{\circ} \mathrm{C}$, taken at two different regions of the same sample. During the reaction, a thick, amorphous mixture of $\mathrm{Ni}$ and $\mathrm{Si}$ has formed. In (a), some unreacted Ni grains are still present at the surface, as well as grains of an unidentified Ni silicide phase. In (b), the entire film consists of the amorphous alloy. Between the film and the pristine Si substrate at the bottom, there is a layer of amorphized $\mathrm{Si}$ due to the implantation process.

the TEM images (Fig. 3) confirm that, due to the implantation process, the Si just beneath the Ni film is entirely amorphous, both before and after annealing the sample to $340{ }^{\circ} \mathrm{C}$.

The conversion of the film to an amorphous phase is also confirmed by the synchrotron XRD measurements, i.e. the film does not give rise to any intense, sharp diffraction peaks (Fig. 4). This XRD spectrum was obtained by probing a large range of orientations (one quarter of a full pole figure) for any given $d$-spacing. The Si substrate peaks were removed from the spectrum by subtracting a similar spectrum of a bare Si sample. The main feature of the spectrum is a very broad, faint peak. The few additional faint peaks might be due to some small crystalline grains that did form (e.g. as in Fig. 3(a)), or might be experimental artefacts due to the large background subtraction. For comparison, the same spectrum is 
FIG. 4. Synchrotron X-ray diffraction of a $35 \mathrm{~nm} \mathrm{Ni}$ film on $\mathrm{Si}(100)$ implanted with $1 \times 10^{16}$ $\mathrm{N} / \mathrm{cm}^{2}$ at $40 \mathrm{keV} /$ atom and annealed at 340 and $440^{\circ} \mathrm{C}$.

shown for a similar sample quenched at $440^{\circ} \mathrm{C}$, in which the film has fully converted to the orthorhombic NiSi phase. The lack of clear diffraction peaks after annealing to $340^{\circ} \mathrm{C}$ implies either that diffraction from the film coincides with that of the substrate (which was excluded in Fig. 4), or that the quenched film is indeed almost entirely amorphous, exhibiting no long-range periodic order. The former possibility could occur if the film was fully converted into an epitaxial, type $\mathrm{A} \mathrm{NiSi}_{2}$ structure. However, an RBS measurement (Fig. 5) reveals that the film contains (on average) $46 \% \mathrm{Si}$, which does not match the 1:2 stoichiometry of a film converted to the $\mathrm{NiSi}_{2}$ phase. In fact, none of the crystalline silicides known from 
FIG. 5. RBS spectrum of a $35 \mathrm{~nm}$ Ni film on $\mathrm{Si}(100)$, implanted with $1 \times 10^{16} \mathrm{~N} / \mathrm{cm}^{2}$ at 40 $\mathrm{keV} /$ atom and annealed at $340^{\circ} \mathrm{C}$, along with simulations of three different film compositions corresponding to the respective stoichiometries of the $\delta-\mathrm{Ni}_{2} \mathrm{Si}, \theta-\mathrm{Ni}_{2} \mathrm{Si}$ and $\mathrm{NiSi}$ phase. The $\theta-\mathrm{Ni}_{2} \mathrm{Si}$ phase $^{1}$ does not have a fixed stoichiometry; its most Si-rich composition $(40 \% \mathrm{Si})$ was chosen. ${ }^{49}$

the Ni-Si phase diagram can account for the measured composition. Simulations of three different film compositions, corresponding to the respective stoichiometries of the $\delta-\mathrm{Ni}_{2} \mathrm{Si}$, $\theta-\mathrm{Ni}_{2} \mathrm{Si}^{1}$ and NiSi phase are shown (Fig. 5) as well; none of them fitting the experimental

${ }^{1}$ The $\theta-\mathrm{Ni}_{2} \mathrm{Si}$ phase can have different compositions, ranging from a $2: 1 \mathrm{Ni}$ :Si ratio (i.e. $\mathrm{Ni}_{2} \mathrm{Si}$ ) up to a $3: 2$ Ni:Si ratio (i.e. $\mathrm{Ni}_{3} \mathrm{Si}_{2}$ ), prompting some authors to refer to the crystalline phase simple as the $\theta$ phase, rather than the more commonly used $\theta-\mathrm{Ni}_{2} \mathrm{Si}$ or $\theta-\mathrm{Ni}_{3} \mathrm{Si}_{2}$ name. ${ }^{8}$ Here, the most Si-rich composition of 
(a)

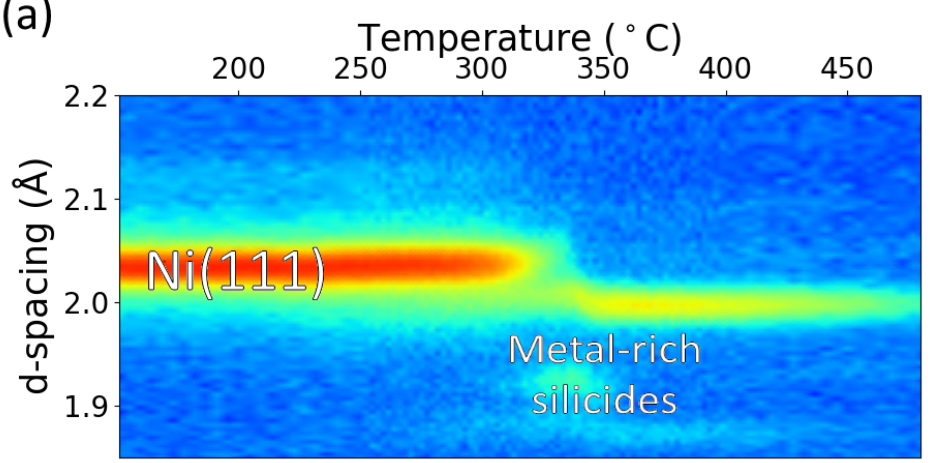

(b)
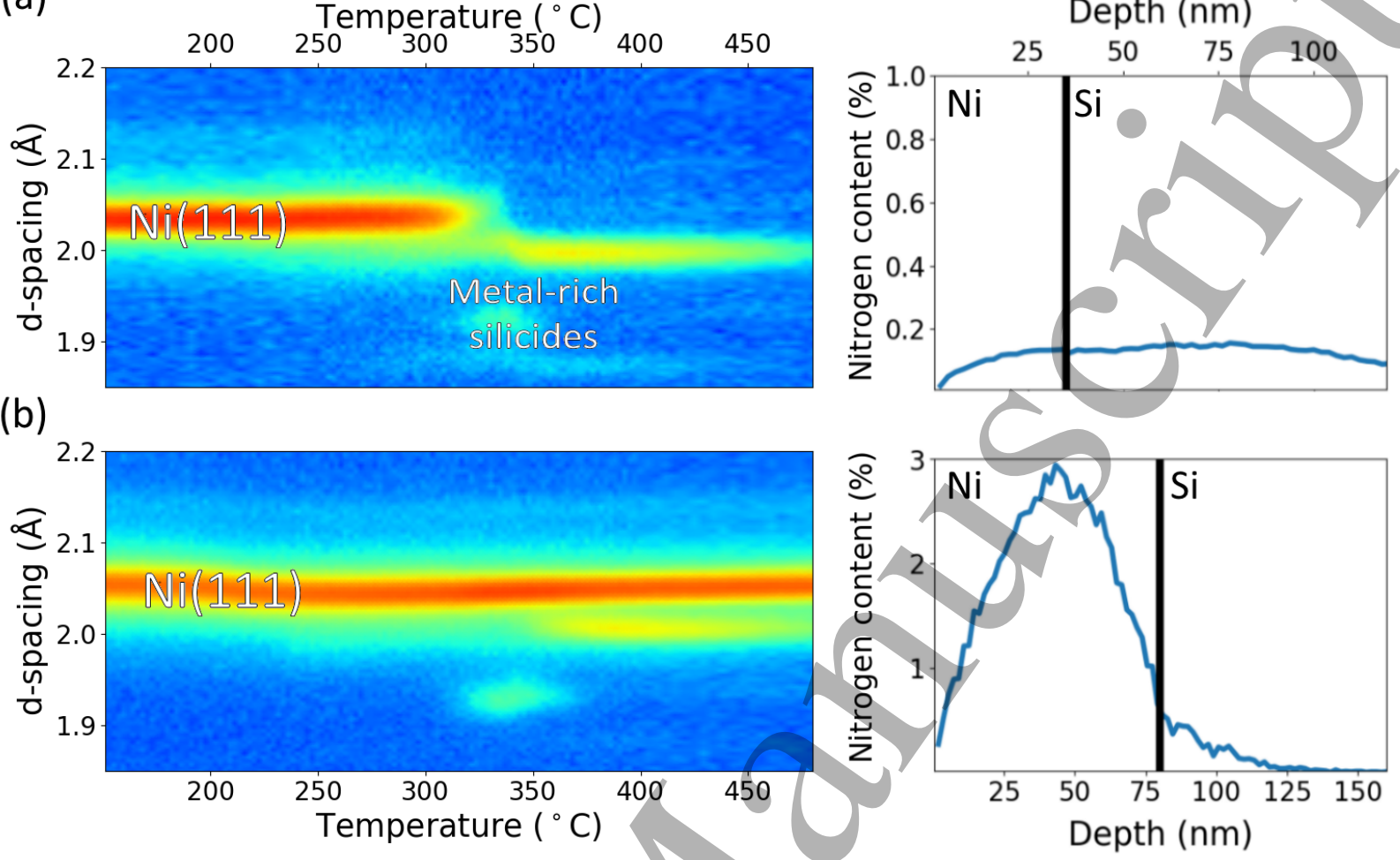

FIG. 6. In situ XRD measurements (left) and distribution of nitrogen throughout the film and substrate after implantation (calculated by TRIM, right) of (a) a $35 \mathrm{~nm} \mathrm{Ni}$ film on Si, implanted with $1 \times 10^{15} \mathrm{~N} / \mathrm{cm}^{2}$ at $40 \mathrm{keV} /$ atom; (b) an $80 \mathrm{~nm} \mathrm{Ni}$ film on Si, implanted with $1.5 \times 10^{16}$ $\mathrm{N} / \mathrm{cm}^{2}$ at $40 \mathrm{keV} /$ atom.

spectrum. However, the composition of the film is very close to the liquidus minimum of the Ni-Si phase diagram, at $46.5 \% \mathrm{Si}^{51}$ Moreover, the film appears to have a compositional gradient, varying from $\mathrm{Ni}$-rich $(44 \% \mathrm{Si})$ at the surface to an almost 1:1 Ni-to-Si ratio $(48 \%$ $\mathrm{Si}$ ) at the interface with the Si substrate. Such a gradient implies that the amorphous phase has a very broad concentration range, unlike line phases such as the $\delta-\mathrm{Ni}_{2} \mathrm{Si}$ or NiSi phases. ${ }^{2}$

the phase is chosen $(40 \% \mathrm{Si})$, to contrast it with the composition of the $\delta-\mathrm{Ni}_{2} \mathrm{Si}$ phase $(33 \% \mathrm{Si})$. 


\section{B. Implantation conditions}

For the SSA reaction described above to occur, specific implantation conditions are required. It is important to note that the introduction of an impurity is crucial. The reaction path described above occurs due to the introduction of nitrogen into the system, rather than due to the ion implantation itself. Indeed, none of our experiments involving argonimplanted or evaporated (amorphous) silicon substrates reproduced such a reaction. By probing a large parameter space of Ar implantation, both before and after film deposition, we assessed the influence of the implantation process, the creation of substrate defects and amorphization, and ion beam mixing on the reaction. In all of these samples, the metal-rich, crystalline phases still form upon annealing. Hence, ion implantation and its concurrent effects (ion beam mixing, defect creation...) are in themselves not the cause of the enhanced SSA reaction. Similarly, evaporating amorphous Si jnterlayers or mixed Ni-Si layers onto Si substrates before depositing a Ni layer did not suppress the growth of the metal-rich phases. In the supplementary information (Figs. S1 and S2), some examples of these measurements are shown.

The only parameter which consistently determines whether the entire film is converted to an amorphous alloy (i.e. the metal-rich, crystalline phases do not form) is the total amount and depth profile of the implanted nitrogen (see below). In other words, ion implantation simply serves as a method of introducing the impurity; another way of introducing nitrogen into the system under the appropriate conditions would very likely yield similar results as described in this paper, e.g. introducing a few percent of nitrogen during evaporation of a silicon interlayer.

If insufficient nitrogen is present at the film/Si interface, the metal-rich, crystalline silicide phases still form upon annealing. This is the case when, for example, too little nitrogen is implanted (Fig. 6(a)) or when most of the nitrogen is implanted too deeply into the Si substrate. Based on our experiments, the threshold of nitrogen at the Ni/Si interface after implantation required for this reaction path lies somewhere between 0.65 and 1.3 at.\% (based on TRIM calculations). It should be noted that nitrogen redistribution may occur during the reaction (on which we have no information). On the other hand, if too much 


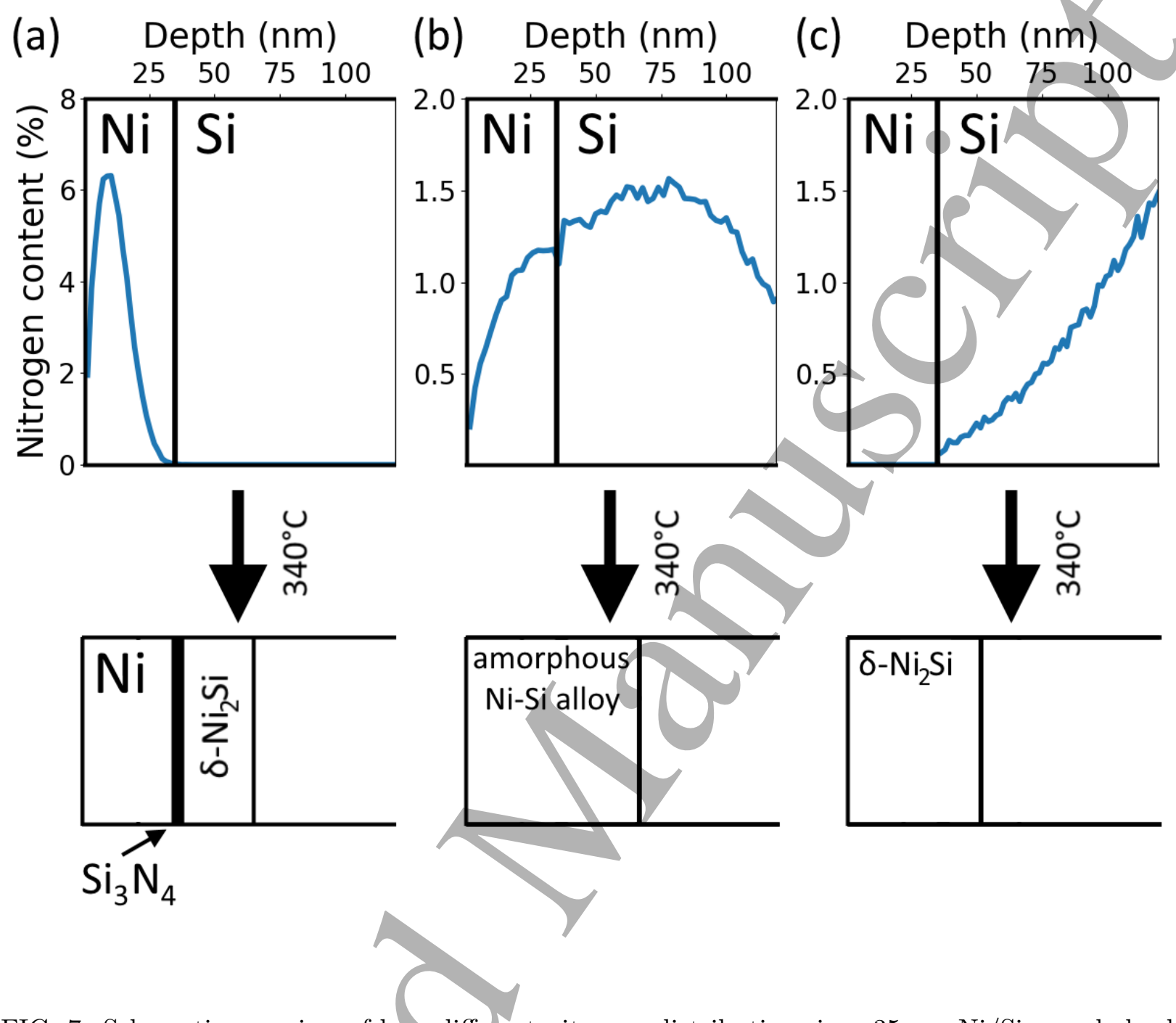

FIG. 7. Schematic overview of how different nitrogen distributions in a $35 \mathrm{~nm} \mathrm{Ni} / \mathrm{Si}$ sample lead to different reaction paths. If $1 \times 10^{16} \mathrm{~N} / \mathrm{cm}^{2}$ is implanted at (a) $7.5 \mathrm{keV} /$ atom, (b) $40 \mathrm{keV} /$ atom or (c) $40 \mathrm{keV} /$ atom prior to Ni deposition, the sample transforms differently upon annealing. The entire film converts to the amorphous phase only if the interface between the film and the Si substrate contains sufficient nitrogen throughout the reaction. This schematic overview illustrates the importance of the initial nitrogen distribution; all examples shown here are based on actual experiments.

nitrogen is implanted into the $\mathrm{Ni}$ layer, a $\mathrm{Si}_{3} \mathrm{~N}_{4}$ diffusion barrier forms, halting the silicide reaction. ${ }^{52}$ Nitrogen is mobile in the metal layer and accumulates at the interface, ${ }^{52}$ either by its own mobility or by a snowplough effect of the moving interface. The combination of mobility and large amounts of nitrogen allows for the growth of a $\mathrm{Si}_{3} \mathrm{~N}_{4}$ barrier, impenetrable to Ni diffusion at these temperatures. This is demonstrated for a film of $80 \mathrm{~nm} \mathrm{Ni}$ on 


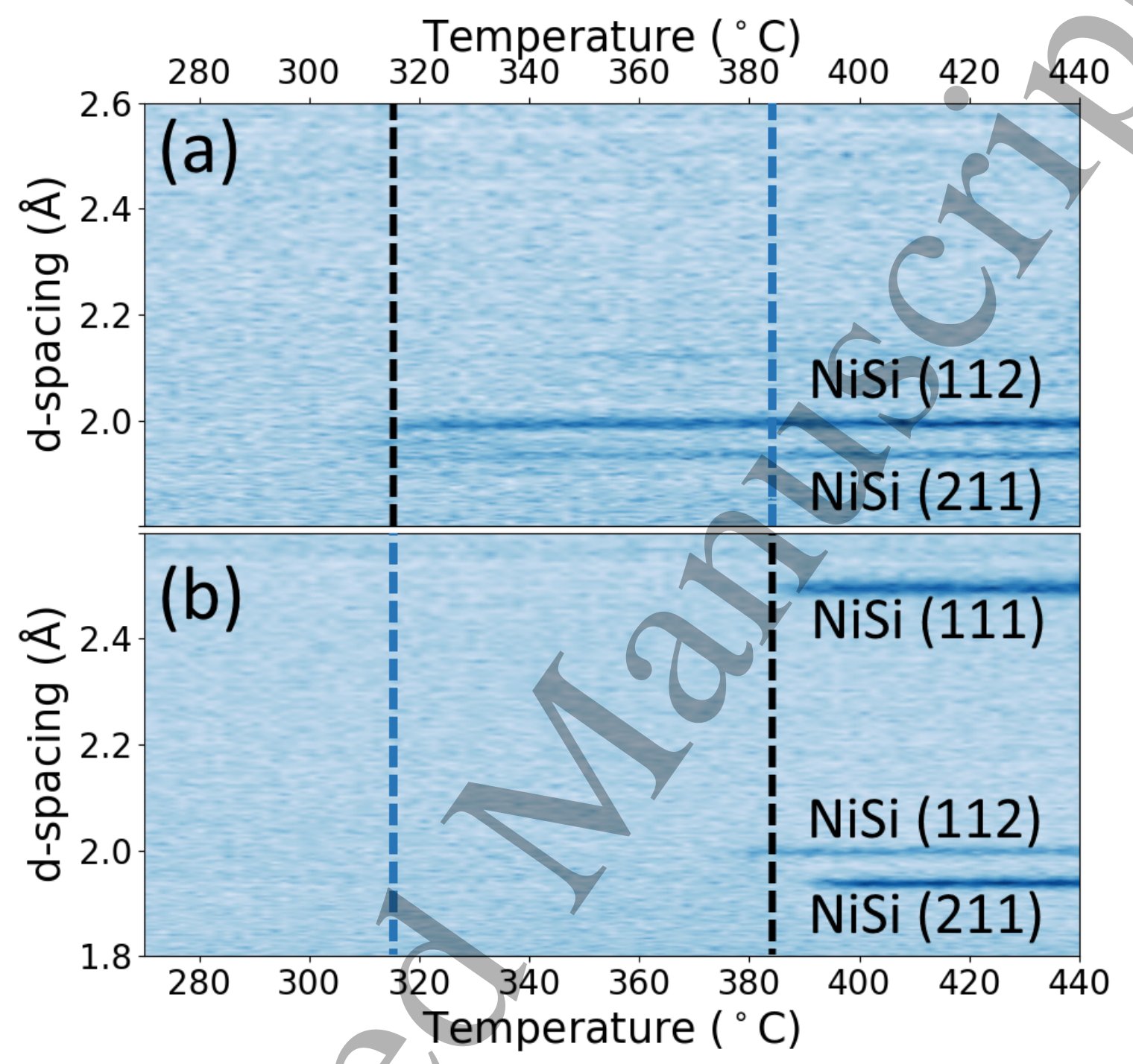

FIG. 8. In situ XRD measurement of the crystallization of an amorphous Ni-Si film (35 nm, $46 \% \mathrm{Si}$ ) deposited onto amorphous $\mathrm{Si}$ and annealed at $0.25{ }^{\circ} \mathrm{C} / \mathrm{s}$, (a) without implantation and (b) with $1 \times 10^{16} \mathrm{~N} / \mathrm{cm}^{2}$ implanted after deposition at $40 \mathrm{keV} /$ atom. Dashed lines indicate the crystallization temperature for both samples.

$\mathrm{Si}$, implanted such that nearly all nitrogen is confined to the Ni layer (Fig. 6(b)). Upon annealing, diffraction from the Ni layer remains present throughout the entire reaction. In summary, the enhanced SSA reaction occurs only when the interface between the film and the substrate contains sufficient nitrogen throughout the reaction (Fig. 7). 


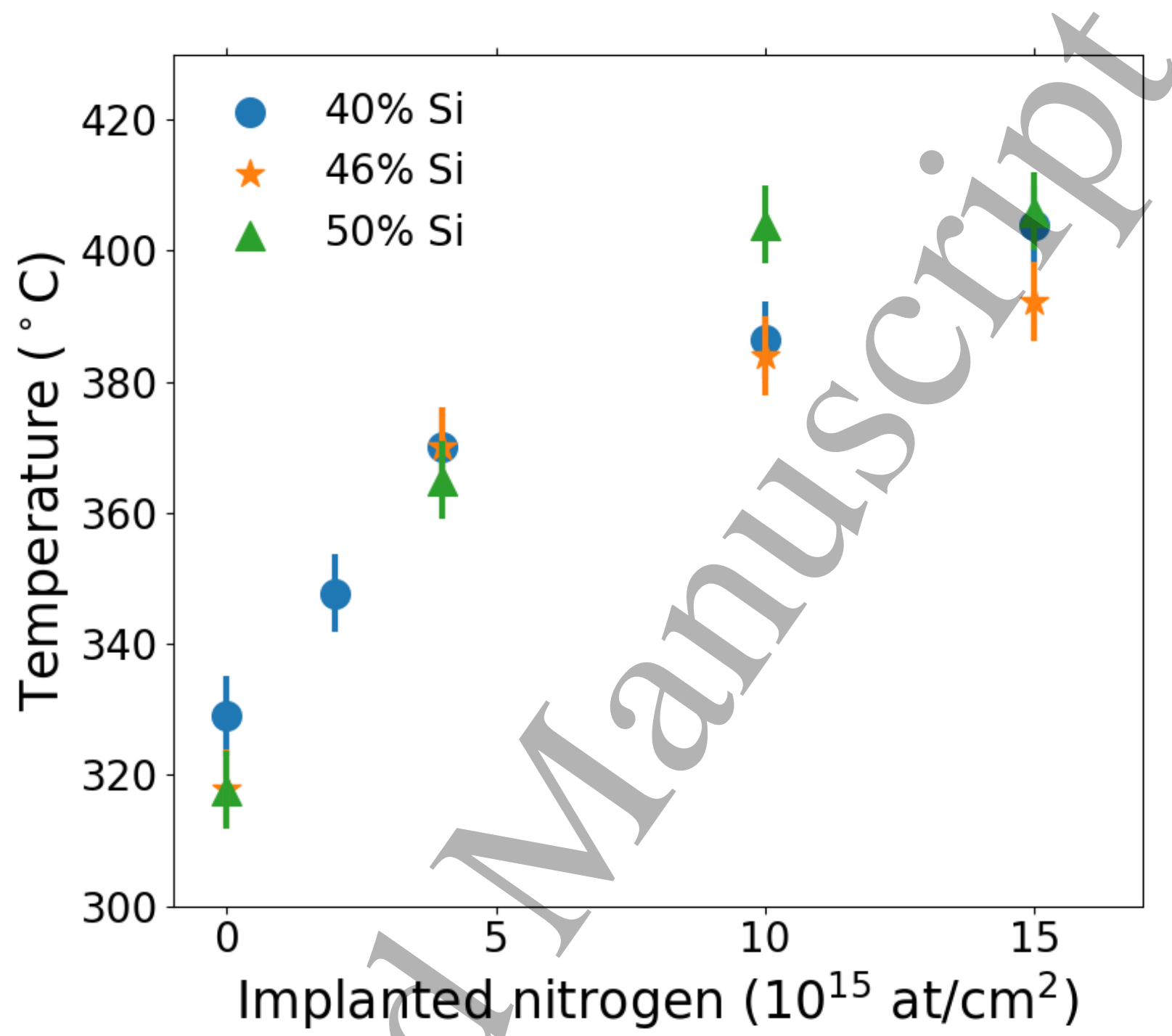

FIG. 9. The NiSi crystallization temperature of amorphous Ni-Si films (with different Si content, all $35 \mathrm{~nm}$ ) on amorphous $\mathrm{Si}$, implanted with nitrogen to varying fluences at $40 \mathrm{keV} / \mathrm{atom}$. Temperatures were derived from in situ XRD measurements, such as those in Fig. 8.

\section{Stability of amorphous phase}

The altered reaction seen in Fig. 2(b) is peculiar for two reasons. The first reason is the suppression of the conventional metal-rich $\delta-\mathrm{Ni}_{2} \mathrm{Si}$ and $\theta-\mathrm{Ni}_{2} \mathrm{Si}$ phases. The second reason is that the amorphous layer remains stable to significantly higher temperatures (at least $340^{\circ} \mathrm{C}$ ) compared to those in unimplanted samples (which crystallize around $235^{\circ} \mathrm{C}$ in contact with unreacted Ni). ${ }^{23}$ However, it is not immediately clear whether this stabilization 
stems from the altered reaction path and its accompanying stresses, moving interfaces, elemental redistribution... or whether the amorphous alloy becomes intrinsically more stable. In other words, does nitrogen stabilize any amorphous $\mathrm{Ni}-\mathrm{Si}$ alloy, or only those growing during the Ni-Si solid phase reaction with a specific stoichiometry?

To answer this question, amorphous films of varying Ni:Si composition were prepared $(40 \%, 46 \%$ and $50 \% \mathrm{Si}, 35 \mathrm{~nm})$ by MBE co-deposition of $\mathrm{Ni}$ and $\mathrm{Si}$ onto an amorphous $\mathrm{Si}$ substrate at room temperature. After deposition, these films were implanted with $\mathrm{N}_{2}$ to several fluences (ranging from 0 to $1.5 \times 10^{16} \mathrm{~N} / \mathrm{cm}^{2}$ ) at $40 \mathrm{keV} /$ atom. This way, the influence of nitrogen implantation on the stability of amorphous $\mathrm{Ni}-\mathrm{Si}$ alloys can be studied directly. Figure 8 shows a comparison between the crystallization of an amorphous Ni-Si (46\% Si) film, without and with nitrogen implantation. Clearly, nitrogen stabilizes the amorphous film: NiSi crystallization is delayed by about $55^{\circ} \mathrm{C}$ after $1 \times 10^{16} \mathrm{~N} / \mathrm{cm}^{2}$ was implanted. Moreover, the stabilizing effect of nitrogen scales with implantation fluence and holds for various Ni:Si ratios, with the layer composition having hardly any influence on the NiSi crystallization temperature (Fig. 9). This suggests that the stabilizing influence of nitrogen on the amorphous phase is not a particularity of the solid-phase reaction of a thin $\mathrm{Ni}$ film on $\mathrm{Si}(100)$, but a general feature of the Ni-Si system.

\section{DISCUSSION}

As mentioned in the introduction, nucleation barriers are responsible for the growth of an amorphous phase in the unimplanted Ni-Si system by suppressing the formation of crystalline phases. This is also the case for the nitrogen-implanted Ni-Si system. Indeed, we have shown that the stabilizing effect of nitrogen on the amorphous phase is a general feature of the Ni-Si system (section III B). The alternative explanation for SSA, the model of growth instability (section IA), relies on moving interfaces and long-range diffusion, which are absent in the crystallization of the as-deposited amorphous layers. Moreover, these nucleation barriers are kinetic in nature, as they are for the unimplanted Ni-Si system, rather than thermodynamic. Nitrogen is unlikely to significantly increase the thermodynamic nucleation barrier $\Delta G^{*}=\frac{\Delta \sigma^{3}}{(\Delta H-T \Delta S)^{2}}$, which is very small for the (unimplanted) Ni-Si system. On the one hand, the effect of 1-2 at.\% of nitrogen in the amorphous layer on the volume terms 
$\Delta H$ and $\Delta S$ will be linear, and consequently, the effect on the nucleation barrier will be on the order of a few percent. On the other hand, nitrogen is expected to lower the interface and grain boundary energy $\Delta \sigma$ of the crystalline phases, ${ }^{53}$ which facilitates nucleation. In short, the origin of the solid-state amorphization reaction for the nitrogen-implanted $\mathrm{Ni}-\mathrm{Si}$ system is the same as that for the unimplanted system, i.e. kinetic nucleation barriers prevent the crystalline phases from forming at lower temperatures. Introducing nitrogen raises these barriers, allowing the amorphous phase to grow until the entire Ni supply is consumed.

Two properties of nitrogen play a role in raising the kinetic nucleation barriers: it is insoluble in any stable, crystalline $\mathrm{Ni}$ silicide, ${ }^{54}$ and it binds strongly with $\mathrm{Si}$, rendering it immobile in the substrate. ${ }^{52}$ The insolubility of nitrogen slows down the formation of crystalline Ni silicides: the volume in which the crystalline nuclei form will contain some (average) amount of nitrogen atoms, which must be segregated from that volume if the phase is to grow. Hence, additional atomic rearrangement, proportional to the amount of implanted nitrogen, is required for the nucleation of crystalline phases. Moreover, the strong nitrogen-silicon bonds must be broken before the impurity can become mobile and (local) redistribution can occur. The reason why nitrogen implantation enhances the amorphization reaction becomes clear. Introduction of a third, insoluble element in the binary system increases the need for atomic rearrangement for nucleation of crystalline phases. Moreover, the ability of the third element to bind strongly to Si renders the impurity immobile, thus reinforcing the kinetic asymmetry between mobile (Ni) and immobile ( $\mathrm{Si}, \mathrm{N})$ elements which lies at the heart of the SSA reaction.

Parallels can be drawn between our results and previous reports which have either confirmed $^{16}$ or suggested ${ }^{44}$ that the amorphous phase at the Ni/Si interface can grow much thicker after contaminating the Si with $\mathrm{C}, \mathrm{N}$ or O. Indeed, the arguments as to why nitrogen causes an enhanced SSA reaction (insoluble in crystalline silicides and forming strong bonds with $\mathrm{Si}$ ) can be applied to carbon ${ }^{55}$ or oxygen ${ }^{56}$ as well. Another related phenomenon to the impurity-enhanced SSA reaction is the recrystallization of silicon. Small quantities $(0.5$ at.\%) of an impurity such as C, N or O can significantly slow down the recrystallization of an amorphous Si layer. ${ }^{50}$ For both transformations, the mobility of Si atoms is the limiting factor, and the (re)arrangement of Si into a crystal lattice is hindered by the addition of 


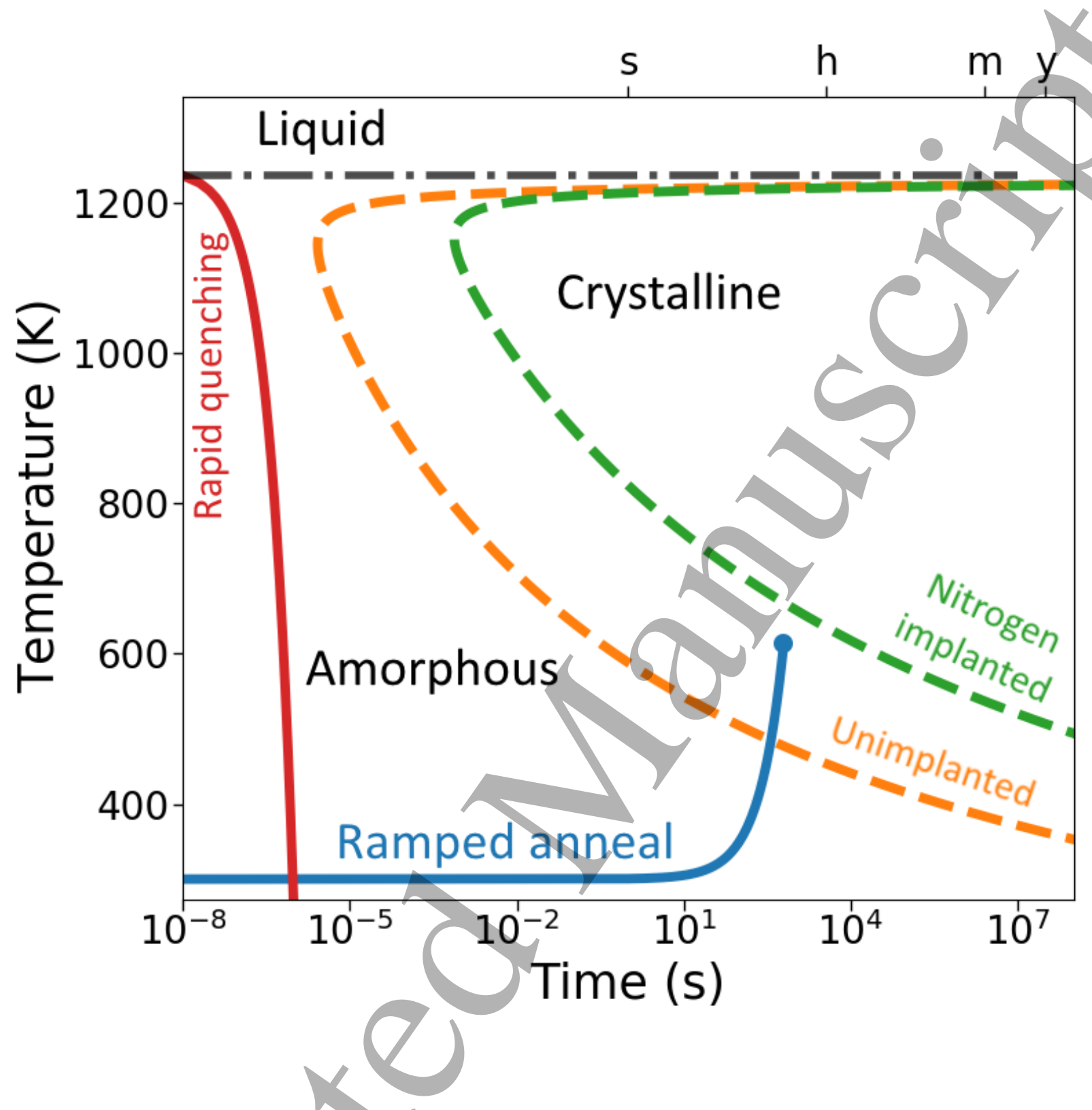

FIG. 10. Schematic time-temperature-transition (T-T-T) diagram, representing the evolution of a Ni film on Si upon annealing (blue solid line). The dashed curves represent the onset of nucleation, with and without nitrogen implantation. At the blue circle, the amorphous phase has consumed the entire Ni supply, if no crystallization takes place. The rapid quenching of a liquid from high temperature (the liquidus minimum of the Ni-Si phase diagram) to an amorphous phase at room temperature is indicated as well (red solid line). The values shown here are only approximate, particularly at temperatures above $650 \mathrm{~K}$; a dedicated study would be required for an accurate time axis. 

$\mathrm{N}, \mathrm{O})$ which are known to retard the recrystallization of $\mathrm{Si},{ }^{50}$ are also those/known $(\mathrm{C}, \mathrm{N})^{16}$ or assumed $(\mathrm{O})^{44}$ to enhance the growth of an amorphous phase during the formation of $\mathrm{Ni}$ silicides. Indeed, the comparison with amorphous Si might be useful in future research. Amorphous Si can store additional energy due to strain, and can subsequently release that energy by relaxing. ${ }^{57}$ The amorphous $\mathrm{Ni}-\mathrm{Si}$ mixture might analogously be in a strained state, either due to the intrinsic stresses associated with a solid-phase reaction, or due to the contained nitrogen, or both. Stresses can have an impact on the precise energy balance of the reaction, albeit a typically limited one. However, studying this is beyond the scope of this study, as the phenomenon of (IE)SSA is rooted in a kinetic barrier, not an energetic one.

We can graphically summarize our results using a time-temperature-transition (T-T-T) diagram (Fig. 10), as is often done for transformations in steel, or for the formation of bulk metallic glasses. In such a diagram, the time needed for a thin layer of a new, crystalline phase to nucleate at different temperatures is plotted (inversely proportional to the nucleation rate, Eq. 1), illustrating the rate of transformation of a system at different temperatures. ${ }^{58}$ At low temperature, the low mobility of the atoms limits the transformation rate from the amorphous to a crystalline phase; the kinetic factor $\mathrm{Q}$ is the dominant barrier to overcome. At higher temperature, the driving force for crystallinity $\Delta G$ decreases as the entropy term T $\mathrm{T} \mathrm{S}$ approaches the enthalpy term $\Delta \mathrm{H}$, reducing the nucleation rate (Eq. 2). As a result, the curves in these T-T-T diagrams typically have a "bell jar" shape (Fig. 10, dashed lines). Forming amorphous films by rapid quenching from the liquid phase, for example, requires cooling rates high enough to avoid intersecting the 'nose' of the crystallization curve. Implantation of nitrogen increases the kinetic term Q in Eq. 1, thus decreasing the nucleation rate at lower temperatures. The blue solid line represents the temperature evolution of the sample during annealing. Its endpoint is the time needed for the amorphous phase to consume the entire Ni supply (if no crystallization occurs). For the unimplanted system, nucleation sets in earlier and the amorphous phase crystallizes. When nitrogen is implanted, however, the point at which the entire film converts to the amorphous phase is reached before any crystalline phase can nucleate. 


\section{CONCLUSION}

We have demonstrated that the reaction of thin Ni films with Si can be significantly influenced by the addition of small amounts of impurities. By implanting nitrogen under the right conditions, the entire $\mathrm{Ni}$ film is converted to an amorphous layer upon annealing. The growth of metal-rich silicide phases is circumvented, as the film converts directly from the amorphous phase to the NiSi phase. Nitrogen stabilizes amorphous Ni-Si films and suppresses nucleation of crystalline phases: more short-range atomic rearrangement is required to form crystalline phases, thus increasing kinetic nucleation barriers.

This effect is likely applicable to other aspects of the Ni-Si system as well. For example, the creation of amorphous $\mathrm{Ni}-\mathrm{Si}$ films by rapid quenching might be facilitated by the introduction of nitrogen, as suggested by the nucleation curves in the T-T-T diagram (Fig. 10); the cooling rate of the sample with nitrogen does not need to be as high as for the unimplanted system. This would be analogous to the creation of bulk metallic glasses, which often include a metalloid or organic element in the mixture of two or more metals to increase the alloy's "glass-forming ability" ${ }^{59}$

Our results illustrate the importance of nucleation barriers and short-range diffusion in the complex early stages of a thin film reaction. These barriers are often overlooked, yet they can have profound effects on the reaction path. Moreover, the ability to tailor these barriers using small amounts of impurities opens up new possibilities of modifying thin film reactions. This is not only scientifically interesting, it is important for applications as well. Several technologically relevant silicide systems undergo solid-state amorphization to some degree, including the $\mathrm{Ni}-\mathrm{Si}$, $\mathrm{Ti}_{-} \mathrm{Si}^{60}$ (contact material for transistors), $\mathrm{Cu}_{-} \mathrm{Si}^{61}$ (barrierless interconnects) and Li-Si ${ }^{62}$ (energy storage) systems. By selecting the optimal impurity and its concentration, one might find ways of enhancing these SSA reactions, leading to new reaction paths and/or new thin film applications. 


\section{ACKNOWLEDGMENTS}

The authors would like to thank C.C. Theron for interesting discussions. The authors are grateful to the FWO Vlaanderen (G.0761.12N) and the KU Leuven BOF (GOA/14/007 and C14/18/074) for providing financial support. We acknowledge SOLEIL for provision of synchrotron radiation facilities and we would like to thank Dr. C. Mocuta for assistance in using beamline DiffAbs. We also acknowledge the contribution of Prof. Mark Ridgway (ANU) who passed away before the work was completed.

\section{REFERENCES}

${ }^{1}$ R. Pretorius, C. C. Theron, A. Vantomme, and J. M. Mayer. Compound Phase Formation in Thin Film Structures. Critical Reviews in Solid State and Materials Sciences, 24:1, 1999.

${ }^{2}$ P. Gas and F. M. d'Heurle. Formation of silicide thin films by solid state reaction. Applied Surface Science, 73:153, 1993.

${ }^{3}$ F. A. Geenen, E. Solano, J. Jordan-Sweet, C. Lavoie, C. Mocuta, and C. Detavernier. The influence of alloying on the phase formation sequence of ultra-thin nickel silicide films and on the inheritance of texture. Journal of Applied Physics, 123(18):185302, 2018.

${ }^{4}$ U. Gösele and K. N. Tu. Growth kinetics of planar binary diffusion couples: "Thin film case" versus "bulk cases". Journal of Applied Physics, 53:3252, 1982.

${ }^{5}$ R. Pretorius, T. K. Marais, and C. C. Theron. Thin film compound phase formation sequence: An effective heat of formation model. Materials Science and Engineering, 10:1, 1993.

${ }^{6}$ A. Vantomme, M.A. Nicolet, and N. D. Theodore. Epitaxial $\mathrm{CoSi}_{2}$ films on $\mathrm{Si}(100)$ by solidphase reaction. Journal of Applied Physics, 75(8):3882-3891, 1994.

${ }^{7}$ C. M. Comrie, Falepin A., O. Richard, H. Bender, and A. Vantomme. Metastable iron silicide phase formation by pulsed laser annealing. Journal of Applied Physics, 95(5):2365$2370,2004$.

${ }^{8}$ S. Gaudet, C. Coia, P. Desjardins, and C. Lavoie. Metastable phase formation during the reaction of $\mathrm{Ni}$ films with $\mathrm{Si}(001)$ : The role of texture inheritance. Journal of Applid Physics, 107:093515, 2010. 
${ }^{9}$ W. L. Johnson. Thermodynamic and kinetic aspects of the crystal to glass transformation in metallic materials. Progress in Materials Science, 30:81, 1986.

${ }^{10}$ R. B. Schwarz and W. L. Johnson. Formation of an Amorphous Alloy by Solid-State Reaction of the Pure Polycrystalline Metals. Physical Review Letters, 51:415, 1983.

${ }^{11} \mathrm{~S}$. Herd, K. N. Tu, and K. Y. Ahn. Formation of an amorphous RhSi alloy by interfacial reaction between amorphous $\mathrm{Si}$ and crystalline Rh thin films. Applied Physics Letters, 42:597, 1983.

${ }^{12}$ C.-D. Lien and M.-A. Nicolet. Impurity effects in transition metal silicides. Journal of Vacuum Science and technology B, 2:738, 1984.

${ }^{13}$ A. S. Zuruzi, D. Z. Chi, and D. Mangelinck. Nitrogen enhanced thermal stability of nickel monosilicide. physica status solidi (a), 214(5):1600710, 2017.

${ }^{14}$ A. Schrauwen, J. Demeulemeester, D. Deduytsche, W. Devulder, C. Detavernier, C.M. Comrie, K. Temst, and A. Vantomme. Ternary silicide formation from Ni-Pt, Ni-Pd and Pt-Pd alloys on $\mathrm{Si}(100)$ : Nucleation and solid solubility of the monosilicides. Acta Materialia, 130:19 - 27, 2017.

${ }^{15}$ J. J. Hauser. Crucial role of residual gases in amorphization of crystalline films. Physical Review B, 32:2887, 1985.

${ }^{16}$ E. Ma, W. J. Meng, W. L. Johnson, M.-A, Nicolet, and M. Nathan. Simultaneous planar growth of amorphous and crystalline Ni silicides. Applied Physics Letters, 52:2033, 1988.

${ }^{17}$ S.-M Lee, D.-S. Yun, I.-T. Nam, J.-Y. Lee, Y.-G. Kim, and S.-G. Chang. Solid-state amorphization behaviour in $\mathrm{Ni} / \mathrm{Zr}$ multilayers with oxygen contamination. Journal of Materials science, 30:3924, 1995.

${ }^{18}$ J. Demeulemeester, D. Smeets, C. M. Comrie, N. P. Barradas, A. Vieira, C. van Bockstael, C. Detavernier, K. Temst, and A. Vantomme. On the growth kinetics of $\mathrm{Ni}(\mathrm{Pt})$ silicide thin films. Journal of Applied Physics, 113:163504, 2013.

${ }^{19}$ D. Mangelinck, K. Hoummada, F. Panciera, M. El Kousseifi, I. Blum, M. Descoins, M. Bertoglio, A. Portavoce, C. Perrin, and M. Putero. Progress in the understanding of Ni silicide formation for advanced MOS structures. Physica Status Solidi A, 21:152, 2014.

${ }^{20}$ F. A. Geenen, K. van Stiphout, A. Nanakoudis, S. Bals, A. Vantomme, J. Jordan-Sweet, C. Lavoie, and C. Detavernier. Controlling the formation and stability of ultra-thin nickel silicides - An alloying strategy for preventing agglomeration. Journal of Applied Physics, 
123(7):075303, 2018.

${ }^{21}$ B. A. Julies, D. Knoesen, R. Pretorius, and D. Adams. A study of the NiSi to NiSi ${ }_{2}$ transition in the Ni-Si binary system. Thin Solid Films, 347:201, 1999.

${ }^{22}$ N. Breil, C. Lavoie, A. Özcan, F. Baumann, N. Klymko, K. Nummy, B. Sun, J. JordanSweet, J. Yu, F. Zhu, S. Narasimha, and M. Chudzik. Challenges of nickel silicidation in CMOS technologies. Microelectronic Engineering, 137:79, 2015.

${ }^{23}$ L. Ehouarne, M. Putero, D. Mangelinck, F. Nemouchi, T. Bigault, E. Ziegler, and R. Coppard. In situ study of the growth kinetics and interfacial roughness during the first stages of nickelsilicide formation. Microelectronic Engineering, 83:2253, 2006.

${ }^{24}$ C. Lavoie, C. Detavernier, C Cabral Jr, F. M. d'Heurle, A. J. Kellock, J. Jordan-Sweet, and J. M. E. Harper. Effects of additive elements on the phase formation and morphological stability of nickel monosilicide films. Microelectronic Engineering, 83:2042, 2006.

${ }^{25}$ B. Imbert, M. Gregoire, S. Zoll, R. Beneyton, S. Del-Medico, C. Trouiller, and O. Thomas. Nitrogen impurity effects on nickel silicide formation at low temperatures New "nitrogen co-plasma" approach. Microelectronic Engineering, 85:2005, 2008.

${ }^{26}$ K. De Keyser, B. De Schutter, C. Detavernier, V.Machkaoutsan, M. Bauer, S. G. Thomas, J. Jordan-Sweet, and C. Lavoie. Phase formation and texture of nickel silicides on $\mathrm{Si}_{1-x} \mathrm{C}_{x}$ epilayers. Microelectronic Engineering, 88;536, 2011.

${ }^{27}$ R. Pretorius, C. C. Theron, T. K. Marais, and H. A. Ras. Evaluation of anomalies during nickel and titanium silicide formation using the effective heat of formation model. Materials Chemistry and Physics, 36:31, 1993.

${ }^{28}$ X. L. Yeh, K. Samwêr, and W. L. Johnson. Formation of an amorphous metallic hydride by reaction of hydrogen with crystalline intermetallic compoundsA new method of synthesizing metallic glasses. Applied Physics Letters, 42(3):242-243, 1983.

${ }^{29}$ K. Samwer. Amorphisation in solid metallic systems. Physics Reports, 161:1, 1988.

${ }^{30}$ U. Gösele and K. N. Tu. "Critical thickness" of amorphous phase formation in binary diffusion couples. Journal of Applied Physics, 66:2619, 1989.

${ }^{31}$ R. W. Bené. A kinetic model for solidstate silicide nucleation. Journal of Applied Physics, 61:1826, 1987.

${ }^{32}$ W. J. Meng, C. W. Nieh, and W. L. Johnson. Maximum thickness of amorphous NiZr interlayers formed by a solid state reaction technique. Applied Physics Letters, 51:1693, 1987. 
${ }^{33}$ R. J. Highmore. Nucleation issues in solid state amorphization. Philosophical Magazine Part B, 62:455, 1990.

${ }^{34}$ F. M. d'Heurle. Nucleation of a new phase from the interaction of two adjacent phases: Some silicides. Journal of Materials Research, 3:167, 1988.

${ }^{35}$ Matthieu Guihard. Étude de phase des systèmes Ni/Si-endommagé et Ni/a-Si, par XRD résolue en temps et nanocalorimétrie. Master thesis, Université de Montréal, 2008.

${ }^{36}$ A. Yu. Kuznetsov and B. G. Svensson. Nickel atomic diffusion in amorphous silicon. Applied Physics Letters, 66:2229, 1995.

${ }^{37}$ K. Holloway, R. Sinclair, and M. Nathan. Amorphous silicide formation by thermal reaction: A comparison of several metal - silicon systems. Journal of Vacuum Science and Technology A, 7:1479, 1989.

${ }^{38}$ H. Mehrer. Diffusion in Solids. Springer-Verlag, 2007.

${ }^{39}$ K. R. Coffey, L. A. Clevenger, K. Barmak, D. A. Rudman, and C. V. Thompson. Experimental evidence for nucleation during thin-film-reactions. Applied Physics Letters, 55:852, 1989.

${ }^{40}$ K. Hoummada, E. Cadel, D. Mangelinck, C. Perrin-Pellegrino, D. Blavette, and B. Deconihout. First stages of the formation of Ni silicide by atom probe tomography. Applied Physics Letters, 89:181905, 2006.

${ }^{41}$ L. A. Clevenger and C. V. Thompson. Nucleation-limited phase selection during reactions in nickel/amorphous-silicon multilayer thin films. Journal of Applied Physics, 67:1325, 1990.

${ }^{42}$ W. H. Wang, H. Y. Bai, and W.K. Wang. Interfacial reactions in Ni/amorphous-Si multilayers. Materials Science and Engineering, A179/A180:229, 1994.

${ }^{43}$ Cédrik Coia. Microstructure and growth kinetics of nickel silicide ultrathin films synthesized by solid-state reactions. PhD thesis, Université de Montréal, 2008.

${ }^{44}$ C. C. Theron, J. C. Lombaard, and R. Pretorious. Real-time RBS of solid-state reaction in thinffilms. Nuclear Instruments and Methods in Physics Research B, 161:48, 2000.

${ }^{45}$ T. Cocolios, M. Huyse, and A. Vantomme. The Institute for Nuclear and Radiation Physics at the University of Leuven. Nuclear Physics News, 27:18-22, 102017.

${ }^{46}$ J. F. Ziegler, M. D. Ziegler, and J. P. Biersack. SRIM The stopping and range of ions in matter (2010). Nuclear Instruments and Methods in Physics Research Section B: Beam Interactions with Materials and Atoms, 268(11):1818 - 1823, 2010. 19th International 
Conference on Ion Beam Analysis.

${ }^{47}$ B. De Schutter, W. Devulder, A. Schrauwen, K. van Stiphout, T. Perkisas, S. Bals, A. Vantomme, and C. Detavernier. Phase formation in intermixed NiGe thin films: Influence of Ge content and low-temperature nucleation of hexagonal nickel germanides. Microelectronic Engineering, 120:168-173, 2014.

${ }^{48}$ C. Mocuta, M.-I. Richard, J. Fouet, S. Stanescu, A. Barbier, C. Guichet, O. Thomas, S. Hustache, A. V. Zozulya, and D. Thiaudière. Fast pole figure acquisition using area detectors at the DiffAbs beamline Synchrotron SOLEIL. Journal of Applied Crystallograhy, 46:1842-1853, 2013.

${ }^{49}$ K. Hoummada, I. Blum, D. Mangelinck, and A. Portavoce. Composition measurement of the Ni-silicide transient phase by atom probe tomography. Applied Physics Letters, 96:261904, 2010.

${ }^{50}$ E. F. Kennedy, L. Csepregi, J. W. Mayer, and T. W. Sigmon. Influence of ${ }^{16} \mathrm{O},{ }^{12} \mathrm{C},{ }^{14} \mathrm{~N}$, and noble gases on the crystallization of amorphous Si layers. Journal of Applied Physics, 48:4241, 1977.

${ }^{51}$ A. Nash and P. Nash. The Ni-Si (Nickel-Silicon) system. Bulletin of Alloy Phase Diagrams, 8:6-13, 1987.

${ }^{52}$ D. M. Scott, L. Wieluński, H. von Seefeld, and M.-A. Nicolet. Retardation and Suppression of Nickel Silicide Formation by $\mathrm{N}+$ Implantation. Nuclear Instruments and Methods, 182/183:661, 1981.

${ }^{53}$ C. Detavernier, R. L. Van Meirhaeghe, H. Bender, O. Richard, B. Brijs, and Maex K. $\mathrm{CoSi}_{2}$ formation in thê presence of carbon. Journal of Applied Physics, 92:1207, 2002.

${ }^{54}$ F. Weitzer and J. C. Schuster. Phase Diagrams of the Ternary Systems Mn, Fe, Co, Ni-Si-N. Journal of Solid State Chemistry, 70:178, 1987.

${ }^{55}$ A. S. Edelstein, D. J. Gillespie, S. F. Cheng, J. H. Perepezko, and K. Landry. Reactions at amorphous SiC/Ni interfaces. Journal of Applied Physics, 85(5):2636-2641, 1999.

${ }^{56}$ P. J. Grunthaner, F. J. Grunthaner, D.M. Scott, M-A. Nicolet, and J. W. Mayer. Oxygen impurity effects at metal/silicide interfaces: Formation of silicon oxide and suboxides in the Ni/Si system. Journal of Vacuum Science and Technology, 19:641, 1981.

${ }^{57}$ J.-F. Mercure, R. Karmouch, Y. Anahory, S. Roorda, and F. Schiettekatte. Dependence of the structural relaxation of amorphous silicon on implantation temperature. Phys. Rev. B, 71:134205, Apr 2005 . 
${ }^{58}$ W. Johnson. Bulk Glass-Forming Metallic Alloys: Science and Technology. MRS Bulletin, 24:42, 1999.

${ }^{59}$ W. H. Wang. Roles of minor additions in formation and properties of bulk metallic glasses. Progress in Materials Science, 52:540, 2007.

${ }^{60}$ S. L. Chiu, Y. C. Chu, C. J. Tsai, and H. Y. Lee. Effects of Ti Interlayer on Ni/Si Reaction Systems. Journal of The Electrochemical Society, 151:G452, 2004.

${ }^{61}$ X. Y. Zhang, X. N. Li, L. F. Nie, J. P. Chu, Q. Wang, C. H. Lin, and C. Dong. Highly stable carbon-doped Cu films on barrierless Si. Applied Surface Science, 257:3636, 2011.

${ }^{62}$ P. Limthongkul, Y.-I. Jang, N. J. Dudney, and Y.-M. Chiang. Electrochemically-driven solid-state amorphization in lithium-silicon alloys and implications for lithium storage. Acta Materialia, 51:1103, 2003. 


\section{SUPPLEMENTARY INFORMATION}

\section{A. The Ni-Si reaction on amorphous or damaged $\mathrm{Si}$}

As mentioned in section IIIB, the remarkable enhanced SSA reaction only takes place when introducing nitrogen impurities, whereas creating crystalline damage via ion implantation or using amorphous $\mathrm{Si}$ is not sufficient to induce the phenomenon. Indeed, after implanting Ar ions into the Si substrate before deposition of the Ni film, the metal-rich $\delta-\mathrm{Ni}_{2} \mathrm{Si}$ phase still forms during the $\mathrm{Ni} / \mathrm{Si}$ solid-phase reaction, both for implantation fluences below and above the amorphization threshold (between 1 and $2 \times 10^{14} \mathrm{Ar} / \mathrm{cm}^{2}$ ) (Fig. S1). Similarly, the crystalline $\delta-\mathrm{Ni}_{2} \mathrm{Si}$ phase is observed in the reaction of Ni films with a $\mathrm{Si}$ substrate onto which a thin amorphous Si layer has been deposited (Fig. S2). Both in the case where the amorphous Si layer is consumed before the entire metal supply is consumed (Fig. S2(a)) or whether some amorphous Si is still present after the entire metal supply is consumed before the film is fully converted to the NiSi phase (Fig. S2(b)), diffraction peaks originating from crystalline Ni silicides can be seen throughout the reaction.

\section{B. Selected area electron diffraction}

As shown by TEM (Fig. 3), the film is converted to a thick, amorphous Ni-Si layer. The non-crystalline nature of the layer in the TEM images was confirmed by selected area electron diffraction (Fig. S3). The area selected for diffraction (Fig.S3(a)) contain only Si (both amorphous and crystalline) and the Ni-Si mixture. The diffraction pattern (Fig. S3(b)) shows only the single-crystalline Si diffraction peaks, with no indication of any other crystalline phase. Using synchrotron XRD (Fig. 4), it was already shown that after nitrogen implantation, the $\mathrm{Ni}$ layer converts to an amorphous layer upon annealing. However, SAED probes the crystallinity on a very small, local scale, providing complementary evidence to synchrotron XRD, which probes a large, lateral area.

\section{Growth of amorphous phase at the interface}

Our measurements show that the Ni film is fully converted to an amorphous phase upon annealing, when nitrogen is implanted under the right conditions (Fig. 5). Moreover, this 
(a)
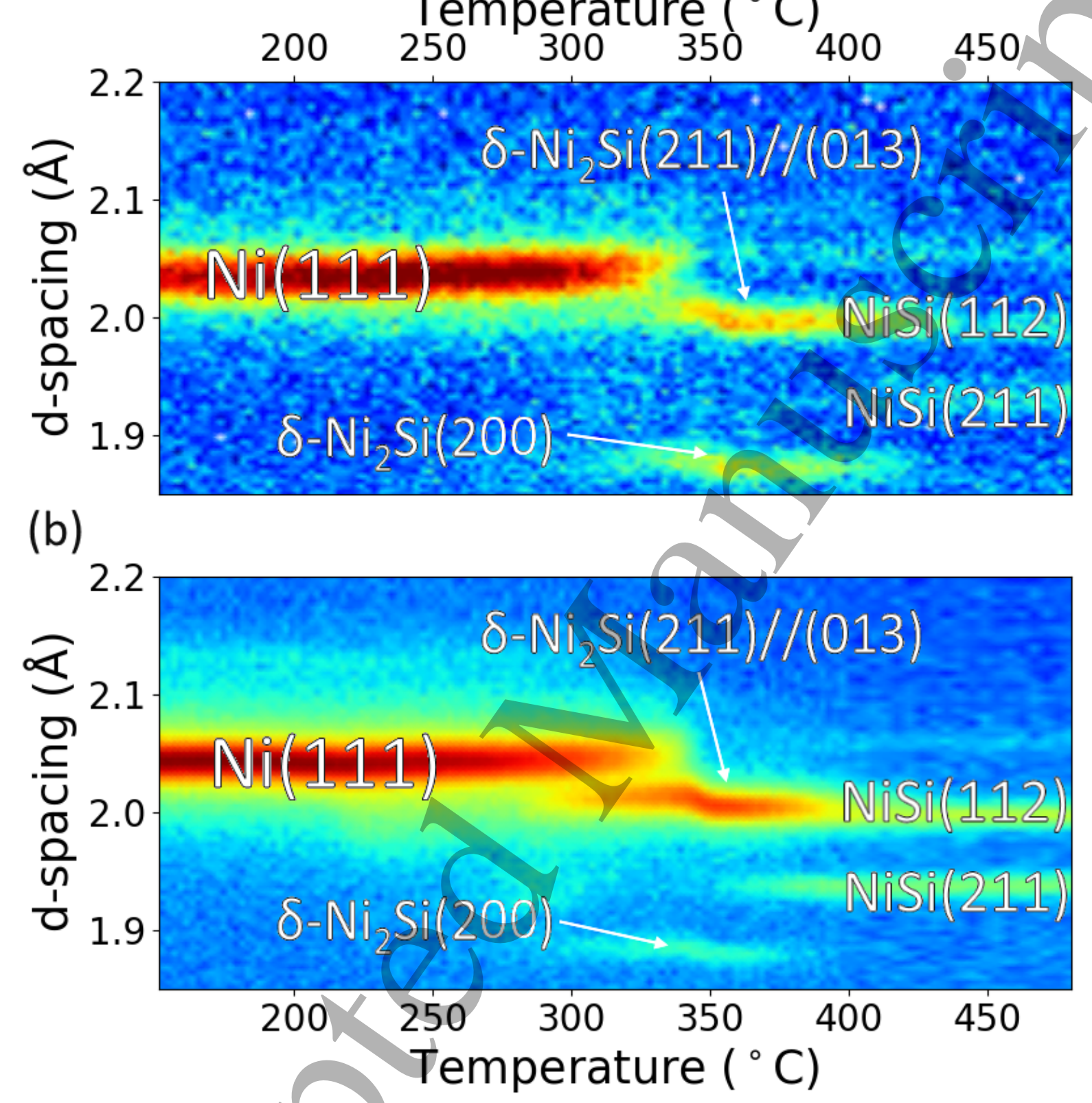

FIG. S1. In situ XRD measurements of the reaction of a $35 \mathrm{~nm} \mathrm{Ni}$ film with a Si substrate that was implanted (prior to film deposition) with (a) $8 \times 10^{13} \mathrm{Ar}^{+} / \mathrm{cm}^{2}$ at $60 \mathrm{keV} /$ atom and (b) $1 \times$ $10^{15} \mathrm{Ar}^{+} / \mathrm{cm}^{2}$ at $60 \mathrm{keV} /$ atom. In (a), the Si near the substrate surface is heavily damaged, but not completely amorphized. In (b), the near-surface Si is completely amorphized. In both cases, the crystalline $\delta-\mathrm{Ni}_{2} \mathrm{Si}$ phase forms, i.e. no impurity-enhanced SSA takes place. 
(a)
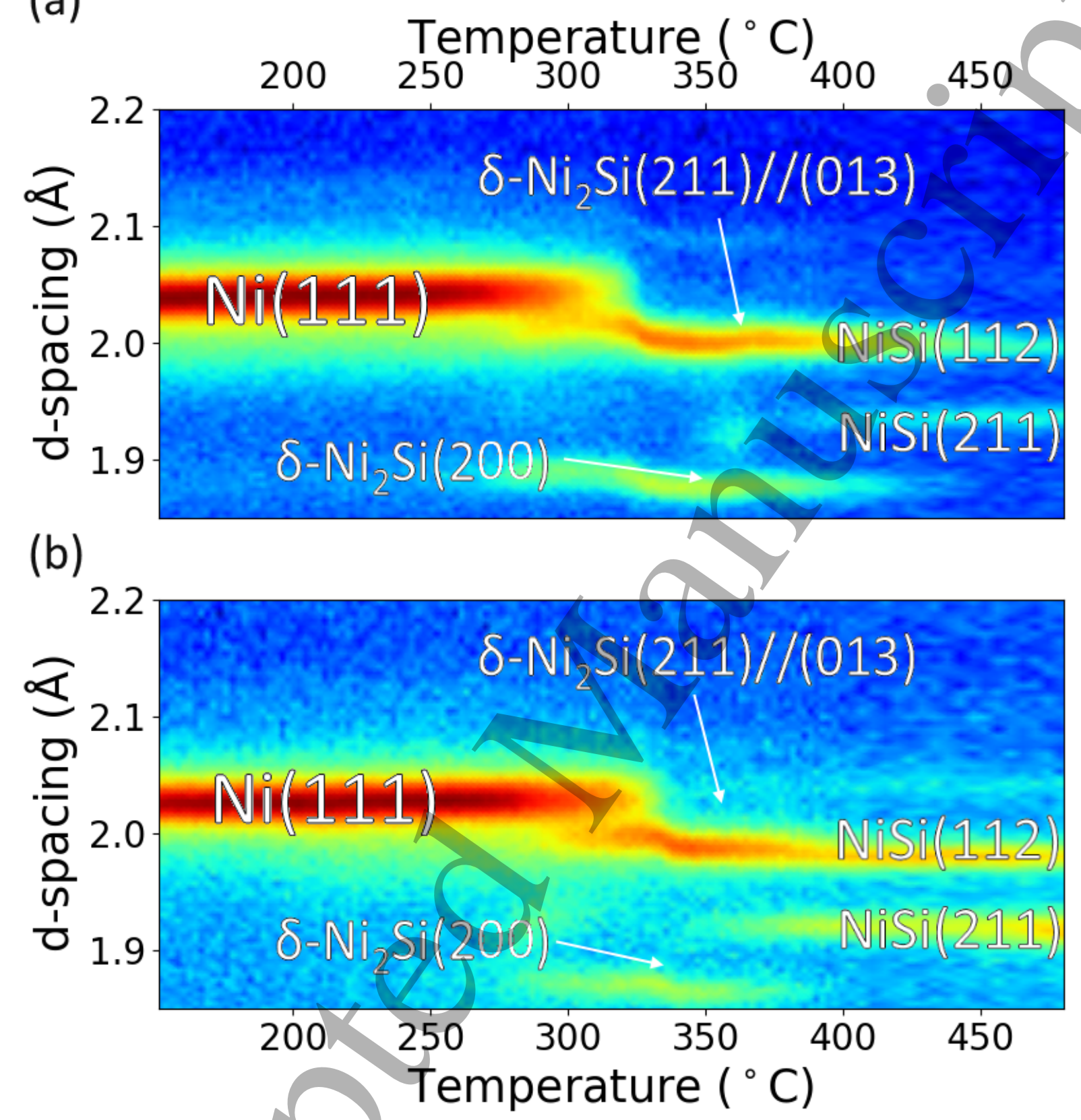

FIG. S2. In situ XRD measurements of the reaction of a $35 \mathrm{~nm} \mathrm{Ni}$ film with a Si substrate onto which an amorphous Si layer (prior to Ni film deposition) was deposited, with a thickness of (a) 20 $\mathrm{nm}$ and (b) $100 \mathrm{~nm}$. For (a), the growth of the $\delta-\mathrm{Ni}_{2} \mathrm{Si}$ (or the Ni-Si phase) phase fully consumes the amorphous Si layer (and some crystalline Si as well). For (b), around $30 \mathrm{~nm}$ of amorphous $\mathrm{Si}$ remains present at the interface, even when all $\mathrm{Ni}$ is consumed and the NiSi growth is complete. In both cases, the crystalline $\delta$ - $\mathrm{Ni}_{2} \mathrm{Si}$ phase forms, i.e. no impurity-enhanced SSA takes place. 
(a)

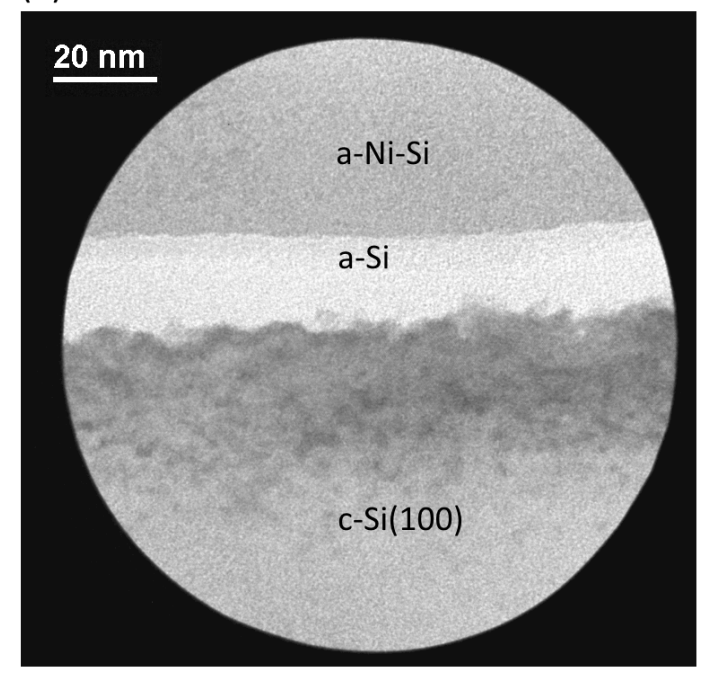

(b)

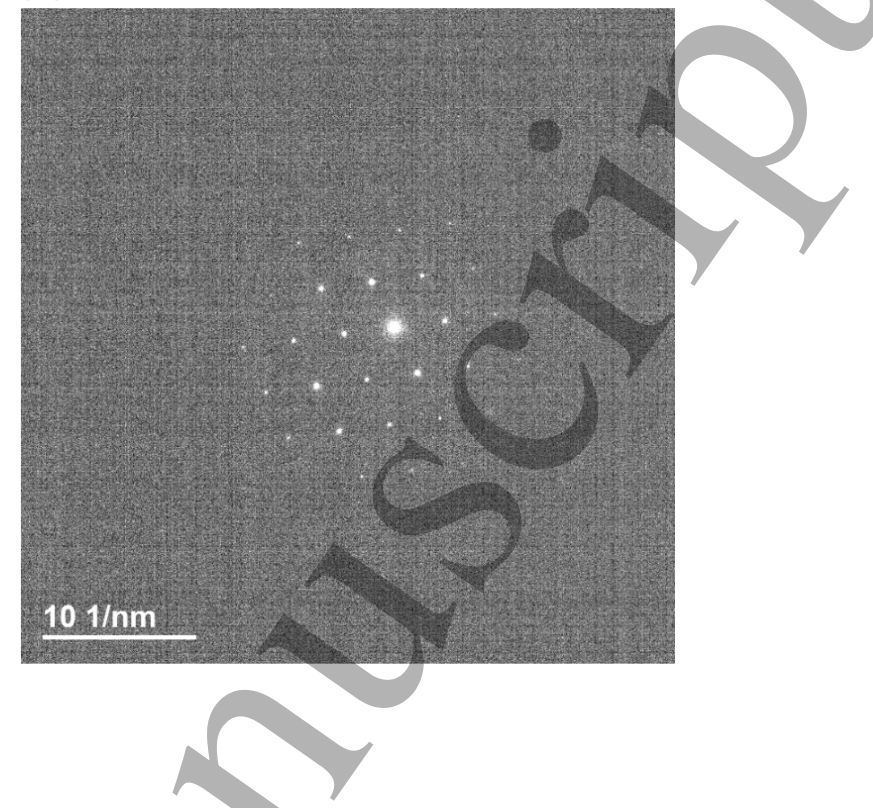

FIG. S3. (a) Selected area of a TEM image of a $35 \mathrm{~nm}$ Ni film on $\mathrm{Si}(100)$ implanted with $1 \times 10^{16}$ $\mathrm{N} / \mathrm{cm}^{2}$ at $30 \mathrm{keV} /$ atom and annealed to $330^{\circ} \mathrm{C}$, used for SAED. It includes the amorphous layer, the amorphous or damaged Si layer (due to ion implantation) and the pristine Si substrate. (b) The SEAD pattern. Only diffraction from the Si substrate is seen, indicating the Ni-Si layer is indeed amorphous.

amorphous interlayer grows as a planar film in a layer-by-layer, as most silicide phases do during solid-phase reactions. To prove this, an RBS experiment (Fig. S4) was performed on a nitrogen-implanted sample which was quenched at $330^{\circ} \mathrm{C}$ (i.e. just before all $\mathrm{Ni}$ was consumed). This measurement shows the amorphous phase grows at the interface between the Ni layer and the substrate. Indeed, the fit indicates the sample consists of a $50 \mathrm{~nm}$ mixture of $\mathrm{Ni}$ and $\mathrm{Si}(46 \% \mathrm{Si}$, assuming the same density as the crystalline NiSi phase) in between a $10 \mathrm{~nm}$ pure Ni layer at the surface and the Si substrate. Furthermore, analysis shows that both interfaces of the amorphous layer are very sharp, each having a roughness of less than $5 \mathrm{~nm}$. This shows the phase grows in a layer-by-layer way, suggesting the layer growth is diffusion-limited, which is characterized by sharp interfaces of the layers and a growth rate proportional to $\sqrt{t}$ in isothermal anneals. Moreover, it shows the composition range (i.e. between 44 and $48 \% \mathrm{Si}$ ) of the amorphous mixture is the same during growth as it is after full consumption of the metal supply. In other words, its stoichiometry is not determined or limited by the amount of $\mathrm{Ni}$ atoms available, but is a fundamental property 


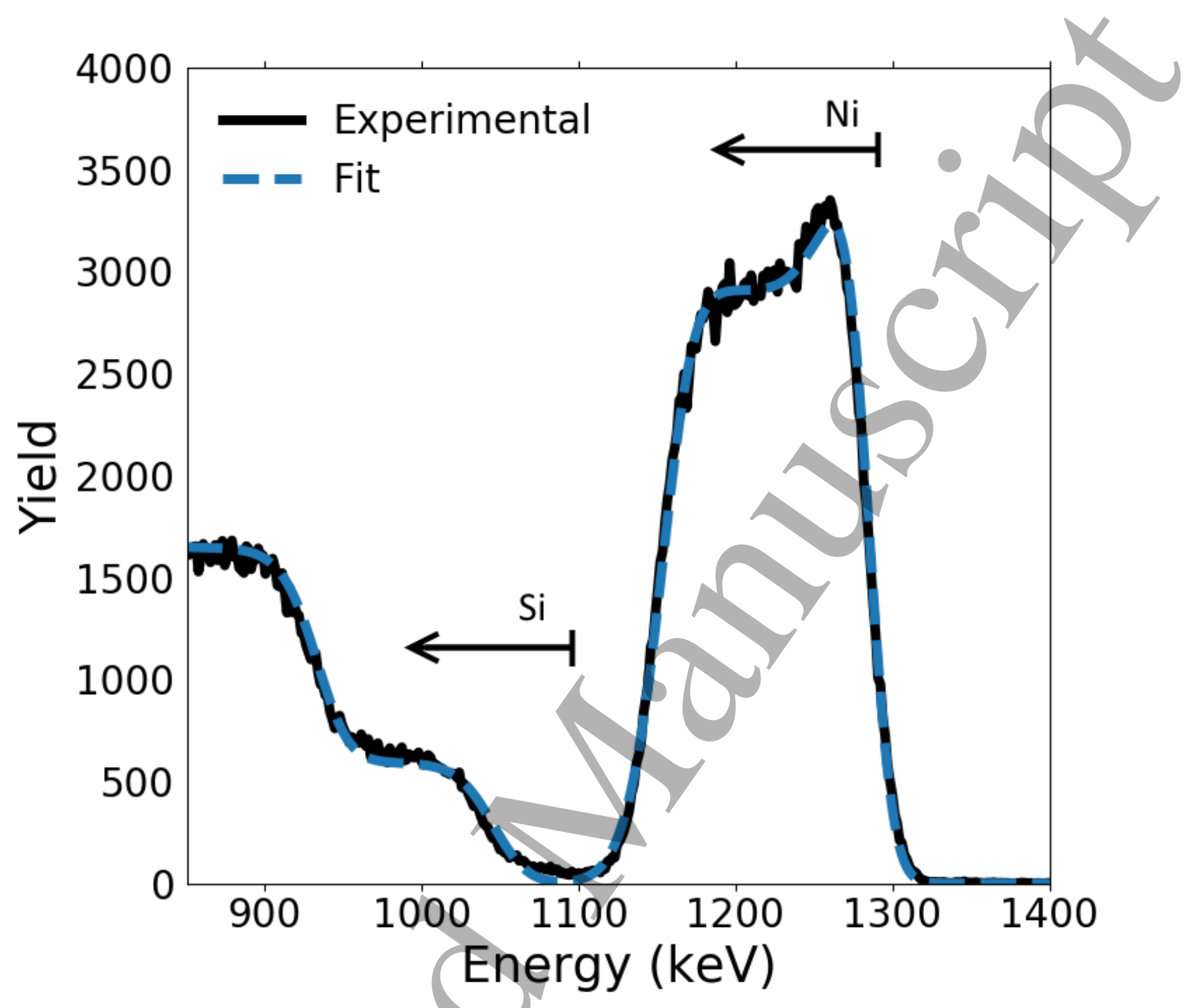

FIG. S4. RBS spectrum of a $35 \mathrm{~nm}$ Ni film on Si(100), implanted with $1 \times 10^{16} \mathrm{~N} / \mathrm{cm}^{2}$ at 40 $\mathrm{keV} /$ atom and annealed at $330^{\circ} \mathrm{C}$, using a scattering angle of $105^{\circ}$ and an energy of $1.57 \mathrm{MeV}$.

of the amorphous Ni-Si phase growing during the solid-phase reaction. 